\title{
Towards local bioeconomy: A stepwise framework for high-resolution spatial quantification of forestry residues
}

\author{
Karan, S.K. ${ }^{1,}{ }^{*}$ and Hamelin, L. $^{1+}$
}

1. Toulouse Biotechnology Institute (TBI), INSA, INRAE UMR792 and CNRS UMR5504, Federal University of Toulouse, 135 Avenue de Rangueil, F-31077, Toulouse, France

* Corresponding Author:

Email: karan@insa-toulouse.fr, Tel.: +33 051-155-9791

+hamelin@insa-toulouse.fr

This is a non-peer review preprint submitted to EarthArXiv. This manuscript has been submitted for publication in Renewable and Sustainable Energy Reviews. Please note that, despite having undergone peer-review, the manuscript has yet to be formally accepted for publication. Subsequent versions of this manuscript may have slightly different content. If accepted, the final version of this manuscript will be available via the 'Peer-reviewed $D O I^{\prime}$ link on the right-hand side of this webpage. Please feel free to contact any of the authors; we welcome feedback.

Shivesh Karan and Lorie Hamelin 


\title{
Towards local bioeconomy: A stepwise framework for high-resolution spatial quantification of forestry residues
}

\author{
Karan, S.K. ${ }^{1,}{ }^{*}$ and Hamelin, L. $^{1+}$
}

1. Toulouse Biotechnology Institute (TBI), INSA, INRAE UMR792 and CNRS UMR5504, Federal University of Toulouse, 135 Avenue de Rangueil, F-31077, Toulouse, France

* Corresponding Author:

Email: karan@insa-toulouse.fr, Tel.: +33 051-155-9791

+hamelin@insa-toulouse.fr

\section{Abstract:}

In the ambition of a transition from fossil carbon use, forestry residues are attracting considerable attention as a feedstock for the future bioeconomy. However, there is a limited spatially explicit understanding of their availability. Confronted with limited resources for extensive field measurement campaigns, there are also limited discussions on the best practices towards a harmonized methodology to derive spatially explicit estimates of forestry residues. In this study, we bridge this gap by developing a generic framework "CamBEE", for a transparent estimation of above-ground primary forestry residues, with a quantification of the uncertainty of the generated estimates. CamBEE is a four-step procedure relying on open access spatial data. Our framework further provides insights on the appropriate spatial resolution to select. Here, we detail this method and provide an example of its application through a case study for France. The results for the case study indicate a total theoretical potential of 8.4 Million Mgdry matter year ${ }^{-1}$ (4.4 - 13.9 Million Mgdry matter year ${ }^{-1}$ ), which deviates of only 32\% (32- $78 \%$ ) from the available statistically-based estimates.

\section{Highlights:}

- CamBEE: A framework for high-resolution spatial quantification of forestry residues

- Uses open-source spatial data \& presents results with uncertainties

- A metric for deciding the spatial resolution for such assessments is provided

- Exemplified results for France reveal 8.4 Million t DM y ${ }^{-1}$ of total availability

Keywords: Bioeconomy; Forest Residues; Spatial Quantification; Theoretical Potential; Uncertainty Assessment; Fossil carbon transition.

\section{List of Abbreviations}

${ }^{\circ} \mathrm{C}$

ALS

BEE

BEF

$\mathrm{CCl}$

CLC

D

d.b.h.

EU

FA

FAO

FRAs

GAI

GIS

GLS

GRECO
Degree Celsius

Airborne Laser Scanning

Biomass Energy Europe

Biomass Expansion Factor

Climate Change Initiative

CORINE land cover

Factor of basic wood density

Diameter at breast height

European Union

Forest Area

Food and Agriculture Organization

Forest Resource Assessments

Gross Annual Increment

Geographic Information System

Global Land Survey

Grandes Régions Écologiques 


$\begin{array}{ll}\text { GUM } & \text { Guide to Uncertainty and Measurement } \\ \text { IPCC } & \text { Intergovernmental Panel on Climate Change } \\ \text { MODIS } & \text { Moderate Resolution Imaging Spectroradiometer } \\ \text { Mgdry matter year }{ }^{-1} & \text { Megagram (1 tonne) of dry matter per year } \\ \text { NAI } & \text { Net Annual Increment } \\ \text { NFIs } & \text { National Forest Inventories } \\ \text { NL } & \text { Natural Losses } \\ \text { NPP } & \text { Net Primary Productivity } \\ \text { PFRs } & \text { Primary Forestry Residues } \\ \text { PJ year }{ }^{-1} & \text { Petajoule per year } \\ \text { SER } & \text { Sylvoécorégions }\end{array}$

\section{Introduction}

Facing the emergency to limit global mean temperature to $1.5^{\circ} \mathrm{C}$ above pre-industrial levels [1], additional releases of fossil carbon must be prevented, and sinks must be induced to achieve so-called carbon neutrality [2], [3]. By using biogenic carbon to supply materials, chemicals, food and energy services, bioeconomy is one option in reaching this balance between anthropogenic emissions and sinks. In particular, the use of biomass residues has generated growing interest as a feedstock not associated with land-use changes [4]-[6], and is likely to have a cheaper cost than conventional biomass, being the by-products of existing operations [7]. Recently, Hamelin et al. [4] highlighted a total (or theoretical) residual biomass potential of 8500 PJ year ${ }^{-1}$ for EU-27 + Switzerland, with forestry residues representing ca. $37 \%$ of this potential.

Forestry residues can be divided into two categories [8]; (i) Primary forestry residues (PFRs), and (ii) Secondary forestry residues. PFRs are defined as residues that are left over from logging operations - thinning or final felling (branches, stumps, treetops, bark, sawdust, etc.). Whereas, secondary forestry residues are by-products and coproducts of industrial wood-processing operations (bark, sawmill slabs, sawdust, wood chips, etc.). This study only focuses on above-ground PFRs (Figure 1). Stumps and roots are excluded given the heavy concerns related to the environmental [9], [10] and economic sustainability of harvesting these [11].

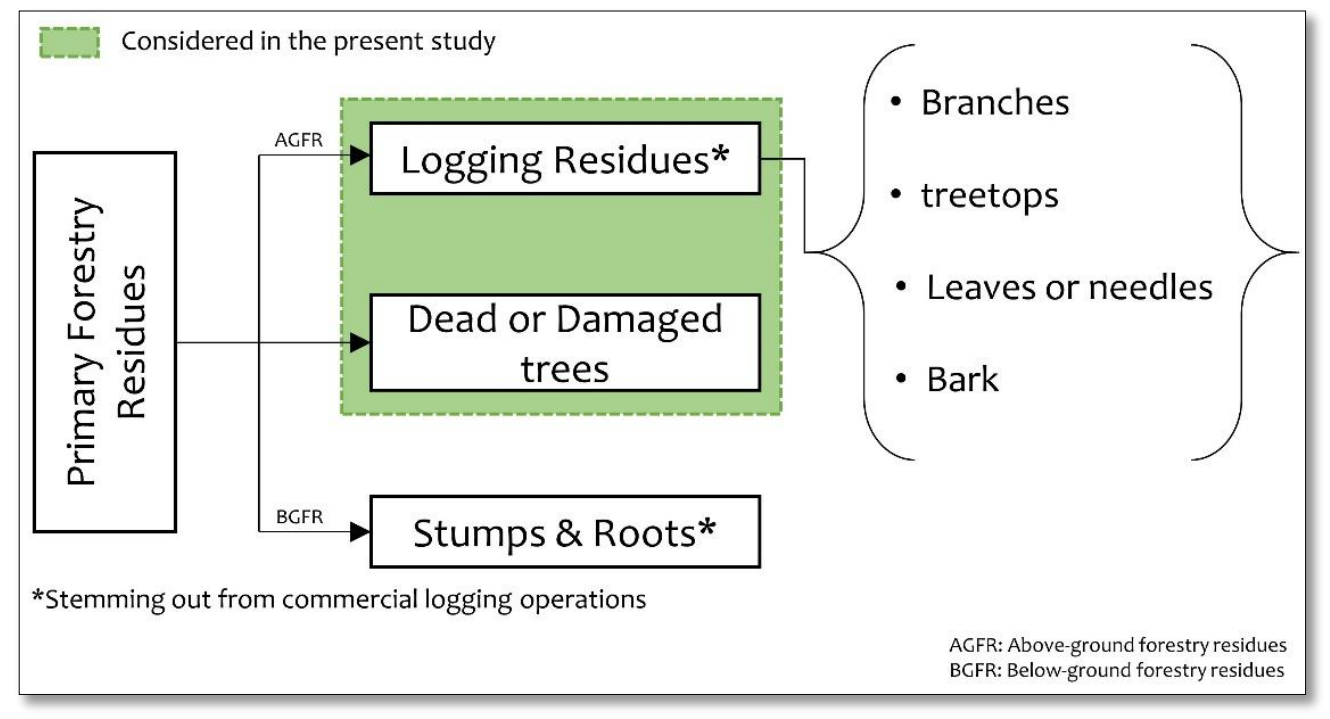

Figure 1: Primary forestry residues (PFR) and streams considered in this study

When it comes to spatial quantification of PFRs, the methods, in general, have improved in the last 10 years, but due to lack of standardization, there is still a major concern in the user community on the methods and practices being used [12], [13]. Apart from this, the availability of forest data on forest classes, species, annual increment, expansion factors, etc. is a major limiting factor for such assessments, as most of the methods do not account for 
these factors. This is especially true for regions with diverse physiography [14]. One well-known forest data inventory is FAO's "Forest Resource Assessments" (FRAs) [15], which provides spatial data on forest statistics. Although valuable, the spatial data provided by FRAs are at best at the country scale, making them unsuitable for high-resolution mapping for use in developing local deployment strategies. In addition to FRAs, the National Forest Inventories (NFIs) also provide comprehensive data on forestry [16]. These data can be useful at sub-regional, regional or country scales, but, at larger scales (Continental or Global) the use of NFls would be erroneous due to the lack of harmonization in definitions and methods [17]. For example, the Swiss NFI only measures trees with the diameter at breast height (d.b.h.) $\geq 12 \mathrm{~cm}$ for quantifying growing stock [18], whereas this threshold is $0 \mathrm{~cm}$ in the reference definition of Cost Action E43 [19].

Furthermore, one vital consideration for spatial quantification is the scale and spatial resolution being used. For geographic information system (GIS) applications, it is common practice to merge datasets through the use of different functions, such as map overlay. But if datasets do not have harmonized spatial resolutions then the result of the operation would be erroneous. In simple words, spatial scale refers to the size of a land area or geographic distance studied. However, there are various categories of scale, such as geographic, operational, measurement and cartographic and it is important that clear distinction is made amongst them. The definition of these terminologies is provided in Table 2. Most studies on spatial quantification do not consider spatial scale as an important parameter, instead, they directly use certain spatial data related to the available methods without questioning the uncertainties associated with them. For example, the use of local forest inventory statistics on a global or continental assessment would lead to a large amount of uncertainty in the analysis due to inconsistencies in geometry, attributes, and semantics owing to scale differences [20]. In fact, when it comes to high resolution mapping of residual biomass resources at country scales, there is no real discussion on what resolution can be considered as useful for bioeconomic purposes.

Globally, very few studies have attempted to spatially quantify the potential of residual biomass from forestry and none of them report the uncertainty associated with the results. Some of these studies are summarized in Table 1 , along with a description of the type of data used and discussions.

[Table 1 here] 


\begin{tabular}{|c|c|c|c|c|c|}
\hline EoA* & Brief detail about the method & Scale, EoA & Year, EoA & Data Used & Discussion \\
\hline$[21]$ & $\begin{array}{l}\text { Based on a mathematical model using } \\
\text { regression parameters and site-specific } \\
\text { input data, including restriction } \\
\text { parameters (e.g. slope, etc.). }\end{array}$ & Province (Spain) & 2009 & $\begin{array}{l}\text { 1. The normal diameter of particular tree species. } \\
\text { 2. Annual increment in diameter of particular tree } \\
\text { species, for the area of interest. } \\
\text { 3. Lower heating value. } \\
\text { 4. Site-specific parameters (Road map, slope map). }\end{array}$ & $\begin{array}{l}\text { - The restriction parameters are highly subjective and lack standards. } \\
\text { - It only considers "usable areas". } \\
\text { - Incorporates site-specific parameters (for technical and economic reasons). } \\
\text { - Uses restriction modeling to estimate the technical potential. } \\
\text { - Appropriate for a theme-based study (e.g., identification of suitable sites to supply a } \\
\text { given thermal power plant). }\end{array}$ \\
\hline [22] & $\begin{array}{l}\text { Based on ancillary data from literature } \\
\text { coupled with GIS soil data and biomass } \\
\text { growth rates. }\end{array}$ & $\begin{array}{l}\text { Sub-regional } \\
\text { (Mozambique) }\end{array}$ & 2009 & $\begin{array}{l}\text { 1. Forest growth data from the literature. } \\
\text { 2. Thematic cartography of soils. } \\
\text { 3. Forest productivity estimation using models from } \\
\text { the literature. } \\
\text { 4. Land-cover map from Landsat data. }\end{array}$ & $\begin{array}{l}\text { - Heavily reliant on data from the literature. } \\
\text { - It does not use any site-specific forestry data. } \\
\text { - Uses arbitrary modeling data from different African regions for simulating results. } \\
\text { - Unclear methodology concerning the estimation of the PFRs, impossible to replicate. }\end{array}$ \\
\hline [23] & $\begin{array}{l}\text { Based on allometric equations and site- } \\
\text { specific forestry data for the evaluation of } \\
\text { PFRs for different tree species. }\end{array}$ & Country (Portugal) & 2010 & $\begin{array}{l}\text { 1. Statistical data for diameter at breast height } \\
\text { (d.b.h.) from field inventory. } \\
\text { 2. The total height of the trees from field inventory. } \\
\text { 3. Statistical data on forestry from literature. }\end{array}$ & $\begin{array}{l}\text { - Almost totally estimated using statistical and allometric equations. } \\
\text { - sails to include a land cover or forest cover map for precise mapping (unless the } \\
\text { incorporate regions specific parameters. } \\
\text { - Useful only for assessment involving different species. } \\
\text { - Discretization at different scales not possible. }\end{array}$ \\
\hline [24] & $\begin{array}{l}\text { Based on remote sensing, forest } \\
\text { descriptive statistics and site-specific } \\
\text { silvicultural model. Uses automated forest } \\
\text { segmentation algorithm developed by } \\
\text { Wells[25] }\end{array}$ & $\begin{array}{l}\text { Regional/Sub-regional } \\
\text { (USA) }\end{array}$ & 2016 & $\begin{array}{l}\text { 1. Remote sensing measurement (Aerial digital } \\
\text { imagery) } \\
\text { 2. Stand characteristics, basal area, tree density, } \\
\text { and above-ground biomass. }\end{array}$ & $\begin{array}{l}\text { - Precise mapping even at sub-regional scale. } \\
\text { - Very high spatial resolution. } \\
\text { - Very high temporal resolution of } 2 \text { to } 5 \text { years. } \\
\text { - Not replicable for use in different areas. }\end{array}$ \\
\hline [13] & $\begin{array}{l}\text { A pixel-based approach that uses long-term } \\
\text { forest inventory data in conjunction with } \\
\text { remote sensing to generate logging residue } \\
\text { availability map. }\end{array}$ & Country (Canada) & 2018 & $\begin{array}{l}\text { 1. Forest attribute maps which include above- } \\
\text { ground biomass and percentage tree cover }(250 \mathrm{~m} \\
\text { resolution)[26] } \\
\text { 2. Annual harvest maps (Specialized product called } \\
\text { CanLaD[27]) }\end{array}$ & $\begin{array}{l}\text { - The method is a potential alternative to expensive field surveys. } \\
\text { - It can be useful in predicting the amount of available logging residues in the future. } \\
\text { - A complex approach that is not easily replicable and uses specialized processed } \\
\text { products like annual harvest maps and forest attribute maps which might not be } \\
\text { available for other regions. }\end{array}$ \\
\hline $\begin{array}{l}{[4],} \\
{[28]}\end{array}$ & $\begin{array}{l}\text { This approach uses the forest map in } \\
\text { conjunction with statistics on NAI and BEF, } \\
\text { through a certain combination of logically } \\
\text { defined equations. This approach This } \\
\text { method is further detailed in section 3.4.1+ } \\
\text { of [29] }\end{array}$ & $\begin{array}{l}\text { Continental } \\
\text { (Europe)[4] } \\
\text { Regional } \quad(\text { Emilia } \\
\text { Romagna/Italy)[28] }\end{array}$ & 2019 & $\begin{array}{l}\text { 1. Raster/Vector data of forest area (ha) } \\
\text { 2. Raster/Vector data of average stemwood net } \\
\text { annual increment per area based on inventory } \\
\text { statistics (Region, Pixel, Raster) } \mathrm{m}^{3} \text { ha }^{-1} \text { year } \\
\text { 3. Wood density for different forest type/species } \\
\left(\mathrm{Mgdrymatter}^{-3} \text { ) }\right. \\
\text { 4. Biomass Expansion Factors }\end{array}$ & $\begin{array}{l}\text { - Estimation involves multiple steps that can affect the accuracy of the estimated } \\
\text { results. } \\
\text { - Clear steps for the estimation of each parameter. } \\
\text { - Can be used for assessment at various scales starting from plot to continental } \\
\text { without compromising accuracy. } \\
\text { - Involves using actual field data along with forest map, thus, making it suitable for a } \\
\text { variety of scales. } \\
\text { - Explicitly described steps make incorporation of uncertainty possible. }\end{array}$ \\
\hline [30] & $\begin{array}{l}\text { This approach uses field data on forest } \\
\text { residual biomass and relates it to several } \\
\text { independent variables extracted from } \\
\text { Airborne Laser Scanner (ALS) to create a } \\
\text { model for quantification of forest residual } \\
\text { biomass using a non-parametric regression } \\
\text { approach. }\end{array}$ & Regional (Spain) & 2019 & $\begin{array}{l}\text { 1. Multi-Year field forest inventory } \\
\text { 2. ALS point cloud data }\end{array}$ & $\begin{array}{l}\text { - Very high spatial resolution, Ideal for sub-regional study. } \\
\text { - Limited coverage (swath) } \\
\text { - Only covers a particular species (Pinus halepensis), hence it may not be suitable for } \\
\text { complex forests with heterogeneous species. }\end{array}$ \\
\hline
\end{tabular}

* EOA: Example of application of the specific method

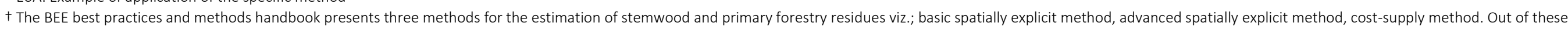
three, only the first one is most transparent in terms of representing actual theoretical potential without any sustainability or feasibility constraints. 
As highlighted in Table 1, researchers have adopted several methods for estimating PFRs. The diversity in these methods is an indicator of the lack of standardization for such assessments. Furthermore, the approaches listed chronologically in Table 1 also highlight how technological improvements in remote sensing over the years have changed the data requirements, with recent methods [13], [24], [30] relying on actual remote sensing measurements than purely being based on certain assumptions and models [21], [22]. However, almost all of the methods listed in Table 1 require field data on forest inventory or statistics for either initializing their model or for validating the results. Field data is essential for robust estimation of PFRs, as the quantity of PFRs is primarily dependent on the harvesting practices, which varies spatially due to several factors such as forest type, harvesting policies, machinery, management practices, etc. Out of all the methods presented in Table 1, only two methods seem promising [13], [29] in the context of large geographic-scale high-resolution mapping. The other methods are either too conceptual and rely primarily on ancillary data from the literature [22], or would be unfeasible to implement for a country scale assessment due to expensive data and processing time [30].

For the country scale (Canada) assessment, Barrete et al. [13] developed an approach to spatially estimate the quantity of logging residues using remote sensing products. They used a set of multi-year harvest maps and a set of forest attribute maps along with inventory data from NFI, and finally, these data were aggregated per hectare of forest area. As reported in their study, the advantage of using this approach would be to have an estimate on the future availability of these residues at a country scale. However, there are several constraints for the application of this method in different regions of the world such as, availability of long-term (decadal) harvest maps, availability for specialized products like "CanLaD", etc., which limits their approach to be reproduced in other regions. However, the shortcomings of this approach can be overcome by using the method provided by Vis and Van den Berg [29], also referred to as the BEE approach in this study. The BEE approach is the most explicit, and amongst the only ones to describe the intermediate steps it uses, making it replicable and adaptable. The other advantage of using this technique is the use of both forest map and forest statistics in the intermediate steps of calculation. This eliminates the need for other assumptions such as regression parameters [21] or allometric equations [23]. Consequently, the use of this method will likely represent the actual ground condition with a minor degree of variability (depending on the quality of the input statistical data) compared to the other techniques listed in Table 1. Even with a constraint like limited availability of inventory statistics, this method can be used to estimate the quantity of PFRs based entirely on remote sensing data products (Forest map from CORINE Land Cover and NPP data from MODIS) with a certain degree of accuracy. Additionally, due to the discrete and flexible nature of the BEE approach, it becomes easier to introduce uncertainty accounting in the intermediate steps of calculation. This allows the final quantification results to have a confidence interval, which grants bioeconomy policymakers to more effectively value the alternatives and make better decisions. Ergo, the present study fully acknowledges and builds upon the efforts and knowledge developed with the BEE method.

From a theoretical viewpoint, spatial estimations are representations, and all representations have their own complexities of reality that cannot be measured directly, which may be termed as potential error or uncertainty. For spatial assessments, uncertainty quantification not only gives a quantified idea about the confidence in calculated results (as ranges); it may also help to understand the spatial pattern of deviation, and ultimately lead to better decision making for the mobilisation of these resources. However, there is a severe dearth of studies incorporating uncertainty analysis in spatial quantification of forest residues; in fact, no literature reporting uncertainty in spatial quantification of forest residues have been found.

In an endeavor to bridge these gaps, the aim of this study is to develop a replicable method for high-resolution spatial quantification of above-ground PFRs at the pixel level along with uncertainty quantification and illustrate how to use it for a concrete case study. This study also proposes a scheme for selecting the optimal resolution for the spatial quantification of PFRs based on several performance criterions. The intention of the methodology produced in this study is to equip bioeconomy policymakers with reliable spatially explicit estimates of this key stream for the future bioeconomy. Besides the investment decision itself, these high-resolution estimates could support decisions such as the siting of a bio-refinery unit.

The paper is structured as follows: Section 2 presents the scope of the present study and refreshes the existing standard definitions of key terms used in this study. Section 3 details the generic stepwise methodological framework we propose for high-resolution spatial quantification of PFRs. Section 4 deals with the exemplification 
of the method. We then critically discuss the results of the study in section 5, especially focusing on the methodological framework and uncertainty associated with different data sources. The discussion section also includes a comparison of the results with other studies and how this work can be improved further. Based on these we conclude how the proposed methodology with uncertainty quantification is a clear step forward towards providing a transparent, replicable, and harmonized methodology for spatial quantification of PFRs.

\section{Scoping}

An important consideration in biomass resource assessment is the type of biomass potential being estimated. The BEE method [29], as well as several other studies e.g. (31,32), distinguish five types of biomass potentials; i.e., theoretical potential, technical potential, economic potential, implementation potential, and sustainable potential. The type of biomass potential being assessed largely determines the approach, methodology, and data requirement [29], [31]. The theoretical potential is generally defined as the maximum overall amount of given targeted biomass that can be considered theoretically available, e.g. for bioeconomy. The other potentials as per their labels, consider some restriction criteria to estimate the biomass resources. From the perspective of strategic decision making at the national level, the theoretical potential is viewed as the most suited, being the most transparent. The estimation of other potentials is usually associated with a certain degree of subjectivity and may apply constraints that could vanish with time, due to changing framework conditions. Hence, this study focuses only on evaluating the theoretical potential for PFRs.

The objective of this study is not to introduce new nomenclature, definition or categorization. However, given the potential confusion related to the use of some key terms, we present in Table 2 the exact definitions considered in this study for all the important terminology.

Table 2: Important terms, definitions, and sources. Definitions are literally extracted from the source.

\begin{tabular}{|c|c|c|}
\hline Term & Definition & Source \\
\hline Above-ground biomass & All living biomass above the soil including stem, stump, branches, bark, seeds, and foliage. & [32] \\
\hline $\begin{array}{l}\text { Biomass Expansion Factor } \\
\text { (BEF) }\end{array}$ & $\begin{array}{l}\text { A multiplication factor that expands growing stock, or commercial round-wood harvest } \\
\text { volume, or growing stock volume increment data, to account for non-merchantable biomass } \\
\text { such as branches, foliage, and non-commercial trees. The BEF is usually calculated from } \\
\text { inventory sources of different forest types (young, secondary to mature), and are defined as } \\
\text { the ratio of total aboveground oven-dry biomass density of trees with a minimum d.b.h. of } \\
\text { "X" cm or more to the oven-dry biomass density total stand volume. }\end{array}$ & [33], [34] \\
\hline Dry Matter & Dry matter refers to biomass that has been dried to an oven-dry state, often at $70^{\circ} \mathrm{C}$. & [32] \\
\hline Felling & $\begin{array}{l}\text { Volume (over bark) of all trees, living or dead, above a } 10 \mathrm{~cm} \text { diameter at breast height, felled } \\
\text { annually in forests or other wooded lands. It includes silvicultural and pre-commercial } \\
\text { thinning and cleanings of trees of more than } 10 \mathrm{~cm} \text { diameter, left in the forest, and natural } \\
\text { losses that are recovered. }\end{array}$ & {$[32]$} \\
\hline Gross Annual Increment & $\begin{array}{l}\text { The average annual increment of volume over the reference period of all trees measured to } \\
\text { a specified minimum diameter at breast height (varies by country). Includes increment of } \\
\text { trees which have been felled or die. }\end{array}$ & [33] \\
\hline Growing stock & $\begin{array}{l}\text { Volume over the bark of all living trees with a minimum diameter of } 10 \mathrm{~cm} \text { at breast height } \\
\text { (or above buttress if these are higher). Includes the stem from ground level up to a top } \\
\text { diameter of } 0 \mathrm{~cm} \text {, excluding branches. }\end{array}$ & [35] \\
\hline High-spatial resolution & $\begin{array}{l}\text { High-spatial resolution can be defined as a measure of the smallest object that can be } \\
\text { distinctly identified; often referred to as a linear dimension on the ground represented by } \\
\text { each pixel. }\end{array}$ & [36] \\
\hline Mortality (Natural Losses) & Trees dying naturally from the competition in the stem-exclusion stage of a stand or forest. & [32] \\
\hline $\begin{array}{l}\text { Net Annual Increment } \\
\text { (NAI) }\end{array}$ & $\begin{array}{l}\text { Average annual volume over the given reference period of gross increment minus natural } \\
\text { mortality, of all trees to a specified minimum diameter at breast height. }\end{array}$ & [33] \\
\hline $\begin{array}{l}\text { Primary Forestry Residue } \\
\text { (PFRs) }\end{array}$ & $\begin{array}{l}\text { Primary Forestry Residues are defined as residues that are left over from logging operations } \\
\text { - thinning or final felling (branches, stumps, treetops, bark, sawdust, etc.) or other pre- } \\
\text { commercial thinning. }\end{array}$ & {$[8]$} \\
\hline Raster data & $\begin{array}{l}\text { In its simplest form, a raster consists of a matrix of cells (or pixels) organized into rows and } \\
\text { columns (or a grid) where each cell contains a value representing information, such as soil } \\
\text { moisture content. Rasters are digital aerial photographs, imagery from satellites, digital } \\
\text { pictures, or even scanned maps. }\end{array}$ & [37] \\
\hline Root to Shoot Ratio & $\begin{array}{l}\text { The ratio of below-ground biomass to above-ground biomass; applies to above-ground } \\
\text { biomass, above-ground biomass growth, biomass removals and may differ for these } \\
\text { components. }\end{array}$ & [32] \\
\hline \begin{tabular}{l|l}
$\overline{\widetilde{U}}$ & Cartographic Scale
\end{tabular} & $\begin{array}{l}\text { Cartographic scale refers to the ratio between the length measurements on a map and the } \\
\text { actual measurements on the ground and is also known as map scale. }\end{array}$ & {$[20]$} \\
\hline
\end{tabular}




\begin{tabular}{|c|c|c|}
\hline Geographic Scale & $\begin{array}{l}\text { Geographic scale or observational scale refers to the size or spatial extent of the study. Ex; } \\
\text { studies of land cover [38] }\end{array}$ & {$[20]$} \\
\hline $\begin{array}{l}\text { Measurement } \\
\text { Scale }\end{array}$ & $\begin{array}{l}\text { Measurement scale, commonly called resolution refers to the smallest distinguishable parts } \\
\text { of an object in a map, such as pixels in remote-sensing images. }\end{array}$ & [39] \\
\hline Operational Scale & $\begin{array}{l}\text { Operational scale refers to the spatial (or temporal) extent at which certain processes } \\
\text { operate in the environment and is also known as process scale or intrinsic scale. The } \\
\text { operational scale of a geographic process can suggest both the geographic and } \\
\text { measurement scale [40] }\end{array}$ & {$[20]$} \\
\hline $\begin{array}{l}\text { Spatial Quantification of } \\
\text { PFRs }\end{array}$ & $\begin{array}{l}\text { Quantification of primary forestry residues in }\left(\mathrm{Mg}_{\mathrm{dry}} \text { matter } \mathrm{year}^{-1}\right) \text { along with positional } \\
\text { attributes (latitude and longitude). }\end{array}$ & This study \\
\hline Stemwood & $\begin{array}{l}\text { The wood of the stem(s) of a tree, i.e., the above-ground main growing shoot(s). Stemwood } \\
\text { includes wood in main axes in major branches where there is at least " } X \text { " } m \text { of 'straight' } \\
\text { length and } Y \mathrm{~cm} \text { top diameter. }\end{array}$ & {$[41]$} \\
\hline Theoretical Potential & $\begin{array}{l}\text { This refers to the maximum energy potential that can be harvested from a resource, given } \\
\text { its physical constraints. }\end{array}$ & {$[42]$} \\
\hline Technical Potential & $\begin{array}{l}\text { It is the share of the theoretical potential that can be harvested taking into account current } \\
\text { harvesting technologies performance and other possible constraints not fully associated } \\
\text { with the physical limiting factor of the targeted source. }\end{array}$ & {$[42]$} \\
\hline $\begin{array}{l}\text { Uncertainty } \\
\text { (of measurement) }\end{array}$ & $\begin{array}{l}\text { A parameter, associated with the result of a measurement that characterizes the dispersion } \\
\text { of the values that could reasonably be attributed to the measurand. }\end{array}$ & {$[43]$} \\
\hline Vector data & $\begin{array}{l}\text { Vector data consists of location, shape, and attributes of geographic features. It is stored as } \\
\text { a set of related files and contains one feature class. Vector data often contain large features } \\
\text { with a lot of associated data. }\end{array}$ & {$[44]$} \\
\hline
\end{tabular}

\section{Method:}

\subsection{Generic Process}

Table 1 highlighted that efforts have already been undertaken to develop methodologies to spatially estimate the PFRs. The approach used here is to build upon the existing efforts, and in particular, upon the landmark BEE handbook technique presented in Vis and Van den Berg [29], also used as an underlying framework for many of the studies carried out post 2010 (Table 1).

However, unlike [29], an in-depth focus on the specific PFR stream and on high spatial resolution is made, data uncertainty and its propagation throughout the calculation process are incorporated, and the use of the methodology is exemplified via a national case study. This translates into a 4-step methodology we here refer to as the CamBEE method for spatial quantification of PFRs (Figure 2). 


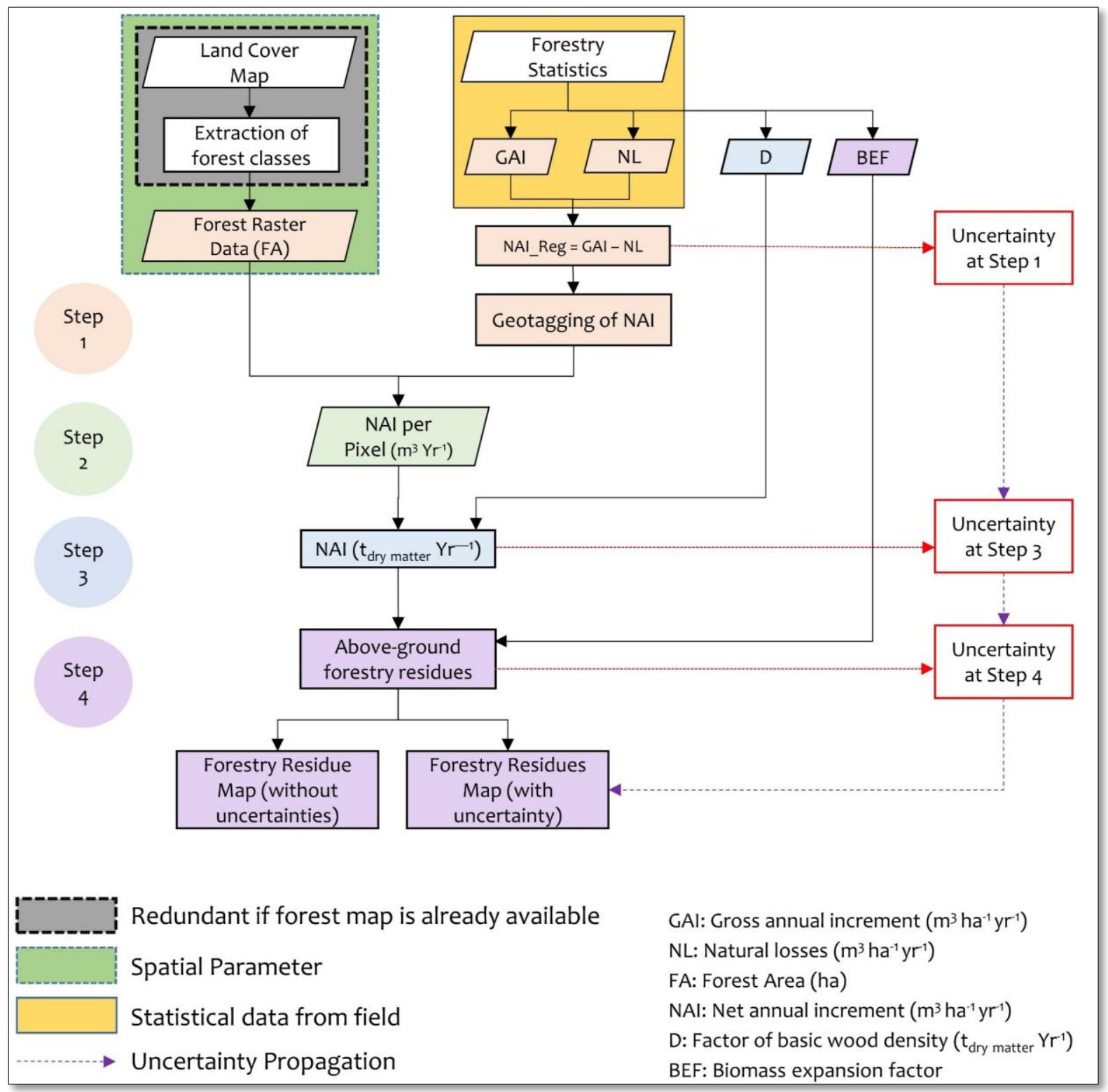

Figure 2: Generic CamBEE stepwise framework for estimation of primary forestry residues with uncertainty quantification

Step 1: Forest map and increment statistics

The first step in the spatial quantification of PFRs involves the estimation of the NAI, which is one of the key input parameters. The NAI provides an indication of the average biomass growth and productivity in a forest. NAI is mathematically defined as the average annual volume gained over the given reference period, also referred to as Gross Annual Increment (GAI), minus the natural losses (NL) on all trees (see definitions of Table 2), as shown in Eq. (1):

$$
N A I_{-} r e g=G A I_{-} r e g-N L_{-} r e g
$$

Where: NAl_reg is the average stemwood NAI per region based on inventory statistics $\left(\mathrm{m}^{3}\right.$ ha $^{-1}$ year $\left.{ }^{-1}\right)$, GAl_reg is the average regional stemwood GAI $\left(\mathrm{m}^{3} \mathrm{ha}^{-1}\right.$ year $\left.{ }^{-1}\right)$ and NL_reg is the average stemwood NL $\left(\mathrm{m}^{3} \mathrm{ha}^{-1}\right.$ year $\left.{ }^{-1}\right)$ per region based on inventory statistics. It should be noted that in an endeavor of harmonization, these notations are kept exactly as they appear in the BEE method [29]. 
The values of GAI and NL can be retrieved from forestry statistical data, e.g., from NFIs which is compulsory in the EU [45]. Furthermore, all 'Annex 1' countries [46] (36 in total, as per the Kyoto protocol) are mandated, since 2000, to publish their annual inventory record online consisting of the national inventory report [47], from which GAI and NL can also be retrieved (at best) or else extrapolated. Alternatively, in regions where these data are not available, the value of NAl can be estimated from Net Primary Productivity (NPP) maps derived from satellite observations [29], [48].

Since the NAI value is a statistical parameter of forest productivity per region that is usually contained as an attribute of a polygon or shapefile, it should be converted to a raster format. Care should be taken in the conversion process and the parameters (cell size and the projection system) should be the same as the forest map raster. The cell size represents the spatial resolution of the raster dataset and ideally, the cell size should be consistent with the spatial resolution of other datasets like the forest map.

Step 2: Fusion of NAl and forest map

In the second step (Figure 2), the forest map raster is fused with the average stemwood NAI per region to get the average stemwood NAI per pixel. The calculation is made as per Eq. (2);

$$
S W_{-} N A I=F A \times N A I_{-} r e g
$$

Where, SW_NAl is the raster of average stemwood NAI per pixel $\left(\mathrm{m}^{3}\right.$ year $\left.^{-1}\right)$ and FA is raster of forest area (ha). The forest map of the area under assessment can be obtained from land-cover data or NFIs, or earth observation data. The forest map provides an understanding of how many hectares of land is under forest with their exact location. Vis and Van den Berg [29] recommend using the forest data with the best possible spatial resolution to get the highest accuracy. Apart from NFIs, this data can be derived from other data platforms such as Global Land Survey (GLS) [49], Climate Change Initiative (CCI) Land Cover V2 [50], GlobeLand30 [51], CORINE Land Cover (CLC) [52], etc., if no other finer regional data can be obtained. As expressed in step 1, care should be taken to ensure consistency in the choice of cell size.

Step 3: Conversion from volume to mass

In the third step, the increment information obtained from step 2 is converted to tonne dry matter (megagram dry matter: Mgdry matter), by multiplying the increment volume and the factor for basic wood density as per Eq. (3);

$$
S W_{-} N A I_{-} t=S W_{-} N A I \times D
$$

Where, SW_NAI_t is the raster of the average stemwood net annual increment $\left(\mathrm{Mg}_{\text {dry }}\right.$ matter year $\left.{ }^{-1}\right)$ and $D$ is the wood density $\left(\mathrm{Mg}_{\text {dry }}\right.$ matter $\mathrm{m}^{-3}$ ). It should be noted that the value of $D$ is unique for every species. The IPCC Good Practice Guidance handbook [53], provides the values for basic wood density for particular species of different forest types (Boreal, Temperate, Tropical) and specifies the sources of these data. These values are usually an average of different observations for a particular species, usually withdrawn from a handbook or in some cases derived from regression equations such as the one in Reyes et al. [54]. When forest maps do not include details about the particular tree species, the BEE method suggests applying average wood density factors at the regional level.

\section{Step 4: Above-ground biomass}

Usually, forest inventories do not measure crown biomass (leaves, twigs, needles, branches), but rather the diameter (at breast height) and height of trees, which is then translated into "stemwood", i.e. the round wood that results from harvesting. As a result, the above-ground biomass produced above X-meter of height (in the form of leaves, twigs, needles, branches) is seldom measured but estimated. This implies that the contribution of these above-ground residues is not registered in the increment raster layer defined in Eq. (3). In inventories, the biomass from leaves/needles, twigs and branches is typically estimated from the NAI with Biomass Expansion Factors (BEF). BEF expands the dry-weight of the growing stock or net annual increment to include the non-merchantable components of the tree, stand or forest [55]. Usually, the BEF is considered as constant or species/area-specific values, but in reality, they are variables [56]. 
Subsequently, in the final step for estimation of PFRs, the raster of biomass increment in foliage and branches is created by fusing the stemwood increment raster (SW_NAI_t) with related BEF for above-ground biomass as per Eq. (4). In Eq. (4), the stemwood increment is subtracted from its product with BEF to produce a raster layer that only includes the information on above-ground forestry residues.

$$
A G F R \_A I_{-} t=\left(S W_{-} N A I_{-} t \times B E F_{-} A b o v e\right)-S W_{-} N A I_{-} t
$$

Where, $A G F R \_A A I_{-} t$ is the raster of average annual increment in biomass from above-ground forestry residues $\left(M_{\text {dry }}\right.$ matter $\left.\mathrm{Y}^{-1}\right)$, and BEF_Above is the average biomass expansion factor for conversion of annual net increment to above-ground tree biomass increment. Here, the notation BEF_Above is simply used in conformity with the notation used in the BEE technique by Vis and Van den Berg [29]. According to Schoene et al. [57], BEF, as withdrawn from the IPCC 2006 guideline (Specifically, Table 3A.1.10) is for estimating the whole tree above-ground biomass only. The values for BEF represent averages for average annual increment or age and is provided as a constant parameter with ranges. The young forest with low growing stock is represented in the upper limit of the range and the lower limit of the range approximates the mature forest with high growing stock.

\subsection{Uncertainty assessment and propagation:}

Usually, environmental data for large geographical scales are assessed by sample-based techniques, as the accounting of each individual tree population is not economical or technically feasible. Statistically, in a samplebased survey, a subset of samples from the population is used to estimate the population parameters based on probability theory. These estimated parameters may differ from the true values as they might be affected by errors such as; sampling errors, assessment errors including classification and measurement errors, prediction errors induced by models, and non-statistical errors [58]. Such errors are common to all assessments and monitoring programs, and these errors have been examined exhaustively in different studies [39], [59]-[61]. Statistically, measurement errors can be categorized into two groups: systematic errors and random errors. The systematic error that is also referred to as bias, is represented as a fixed value for the discrepancy with the true value and is directly related to the accuracy of an estimate. Theoretically, a systematic error can be eliminated from the result by using an appropriate correction factor [62]. However, in sample-based surveys, the presence of bias, which is the lack of accuracy, is often unknown, and using a correction factor may introduce an additional uncertainty associated with that corresponding correction factor. Random error, on the other hand, indicates that the error changes over the period of measurement, or may be transferred from one set of measurements to the other. The range of these changes is a measure of the uncertainty created by these errors. Below we focus on estimating the uncertainties only associated with the random errors of measurement.

From Figure 2, it can be observed that the final output is determined by establishing three functional relationships, where the output of the preceding step is the input for the successive step. When parameters are derived through a series of functional relationships, the uncertainties in the inputs of these functions will propagate through the calculation, in the form of random errors [43]. These uncertainties were accounted for based on state-of-the-art uncertainty propagation techniques, as comprehensively detailed in e.g. [63].

The first step in the uncertainty assessment deals with its propagation in the calculation of NAl_reg through Eq. (1). As the inputs variables (GAI and NL) are uncorrelated, we proceed by evaluating the standard uncertainty for the function in Eq. (1), using Eq. (5). For a generic function $y=x_{1}-x_{2}$ where $x_{1}$ and $x_{2}$ are uncorrelated, as per the Guide to Uncertainty and Measurement (GUM) [43], the uncertainty can be expressed as:

$$
u^{2}(y)=u^{2}\left(x_{1}\right)+u^{2}\left(x_{2}\right)
$$

Where, $u^{2}(y)$ is the squared standard uncertainty (numerically and mathematically equal to variance) in $y$, and $u^{2}\left(x_{n}\right)$ is the standard uncertainty squared for a given $x$ variable. The variable $x_{1}$ here corresponds to the GAl_reg values and the variable $x_{2}$ corresponds to the NL_reg values. For cases where the standard deviation of NAI is provided, uncertainty propagation using Eq. (5) would be redundant and the uncertainty assessment should then start from the next step.

The uncertainty from Eq. (5) is then propagated to the calculation of average stemwood NAl in $\mathrm{Mgdry}_{\text {matter }}$ year ${ }^{-1}$ through the functional Eq. (3). To account for the uncertainty in the functional Eq. (3), we use the expression giving 
the standard uncertainty in Eq. (6). For the generic function, $y=A x_{1}$ where ' $A$ ' is a constant and $x_{1}$ is a measured variable, as per the GUM [43], the uncertainty can be expressed as:

$$
u^{2}(y)=A^{2} u^{2}\left(x_{1}\right)
$$

Where, $u^{2}(y)$ is the squared standard uncertainty in the measurand $y$, and $u^{2}\left(x_{n}\right)$ is the standard uncertainty squared in the variable $x$. The variable $x_{1}$ in Eq. (6) corresponds to the NAl that is propagated through Eq. (5) and the constant $A$ corresponds to the factor of basic wood density $(D)$. The value of $D$ is considered as a constant and represents the mean of the $D$ for different tree species of a particular forest class. To evaluate the uncertainty coming from the range of $D$, Eq. (6) is calculated with its maximum and minimum values.

Finally, the uncertainty from Eq. (6) is propagated in the calculation of above-ground forestry residues. Eq. (4) has two arithmetic operations, and its generic structure is $y=A x_{1}-x_{1}$. Therefore, the uncertainty for this step is evaluated in two stages. The first stage follows the uncertainty expression in Eq. (6), and the second stage follows the uncertainty expression in Eq. (5). The first stage relates to the BEF parameter, which is provided as ranges. In order to encompass the entire range of the BEF in the uncertainty, the calculation is conducted by incorporating the maximum and minimum values of BEF. The second stage follows the uncertainty expression in Eq. (5), where, the data incorporating the uncertainties from the BEF is merged with the uncertainty of NAI in Mgdry matter year ${ }^{-1}$. This ultimately provides the uncertainty that gets propagated in the spatial quantification of above-ground forestry residues.

Here, there are two non-constant statistical input variables of forestry from which uncertainty propagates, viz., GAI_reg and NL_reg (or NAI_reg if NAI is directly available). Ideally, the standard deviation associated with these values will be provided (or the raw measurement datasets to derive it), and this can be used as the value of " $u$ " in Eqs. 5-6. In cases where no indications of the standard deviation are provided, techniques are available to derive an uncertainty. Notably, the pedigree matrix technique [64] was developed in the field of life cycle assessment, where such a situation is common.

\section{Exemplification of the use of the CamBEE method}

\subsection{Study Area}

To exemplify the proposed technique, we present a case of Metropolitan France (Mainland European France including Corsica), herein referred to France. France is administratively divided in the following hierarchy: Regions (13) > Departments (96) > Communes (36569), though other administrative or political areal units also exist.

France is a key country for the European bioeconomy [65] and accounts for almost 10\% of the European forest cover and has the fourth largest area in the EU behind Sweden, Finland, and Spain [66]. In France, forests cover approximately $168000 \mathrm{~km}^{2}$ or about $30.8 \%$ of the total French territory and are dominated by Temperate and Mediterranean type forests [67]. About $\approx 76 \%$ of the total forest in France is privately owned ( $\approx 64 \%$ by individuals and families and $\approx 12 \%$ by private industries) [68]. The remaining $24 \%$ of the forests are owned by the French government, out of which about $14 \%$ is communal (belonging to the municipal or other local authorities) and $10 \%$ is provincial (belonging to the state) [68], [69]. The public forests nevertheless account for $40 \%$ of the timber harvest [70]. In the present exemplification, the annual availability of PFRs for both privately owned and public forests were determined. The vision is that this may serve as a piece of key information to facilitate eventual decisions related to the mobilization of PFRs from the perspective of national bioeconomy strategies. Additional details on French forestry are available in the supplementary materials.

To estimate above-ground PFRs the CamBEE method requires five main input data, viz., the forest cover raster; forest statistics on gross annual increment (GAl) and natural losses (NL) if net annual increment (NAI) is not available per region; factor of basic wood density (D), and biomass expansion factor (BEF). Other ancillary data required for mapping are the administrative shapefile (e.g. country or regional boundary). The source of data used in the present study is provided in Table 3. 
Table 3: Source of data used in the present study

\begin{tabular}{|c|c|c|c|}
\hline Data Type & Used for & Source & Time scope \\
\hline Forest Cover & Used in Step 2 of the CamBEE process & [71], [72] & $<2018$ \\
\hline $\begin{array}{l}\text { Forest Inventory } \\
\text { Statistics }\end{array}$ & Used in Step 1 of the CamBEE process & {$[73]$} & $2009-2014$ \\
\hline $\begin{array}{l}\text { Biomass Expansion } \\
\text { Factors (BEF) }\end{array}$ & Used in Step 4 of the CamBEE process & $\begin{array}{l}\text { Table 3A.1.10; } \\
\text { [53] }\end{array}$ & $<2003^{+}$ \\
\hline $\begin{array}{l}\text { Factor of basic wood } \\
\text { density (D) }\end{array}$ & Used in Step 3 of the CamBEE process & $\begin{array}{l}\text { Table 3A.1.9-1; } \\
\text { [53] }\end{array}$ & $<2003^{+}$ \\
\hline Administrative shapefile & Used in the exemplification section & [74] & - \\
\hline EPCI ${ }^{1}$ Shapefile & Used for extracting the inventory statistics data in the exemplification & [75] & - \\
\hline $\begin{array}{l}\text { Public / Private forest } \\
\text { shapefile }\end{array}$ & $\begin{array}{l}\text { Used for identifying the publicly owned and the privately owned } \\
\text { forests of France in the exemplification section }\end{array}$ & {$[76]$} & - \\
\hline
\end{tabular}

${ }^{1}$ A French administrative regional unit that groups several communes based on some of their common competences. There are $1258 \mathrm{EPCl}$ in France (as of $1^{\text {st }}$ January 2019).

+ The values of BEF for different forest types were obtained from the IPCC good practice Guidance report [53]. The report takes these values from several references that are from the 1990s. For D, as these values are specie-specific, their values in the IPCC report was also taken from several references, some of which were from 1968.

For the present study, the BD Forest ${ }^{\oplus}$ V2 data [71] was used for FA. The BD Forest ${ }^{\oplus}$ V2 data is the most comprehensive forest data in France, which can be downloaded in vector (GIS) format and contains 32 forest classes based on a hierarchical structure. These were aggregated to three forest classes (Conifers, Broadleaf, and Mixed) as illustrated in Figure 3. An example of aggregation for the Occitanie region of France is shown in Supplementary Figure 1.

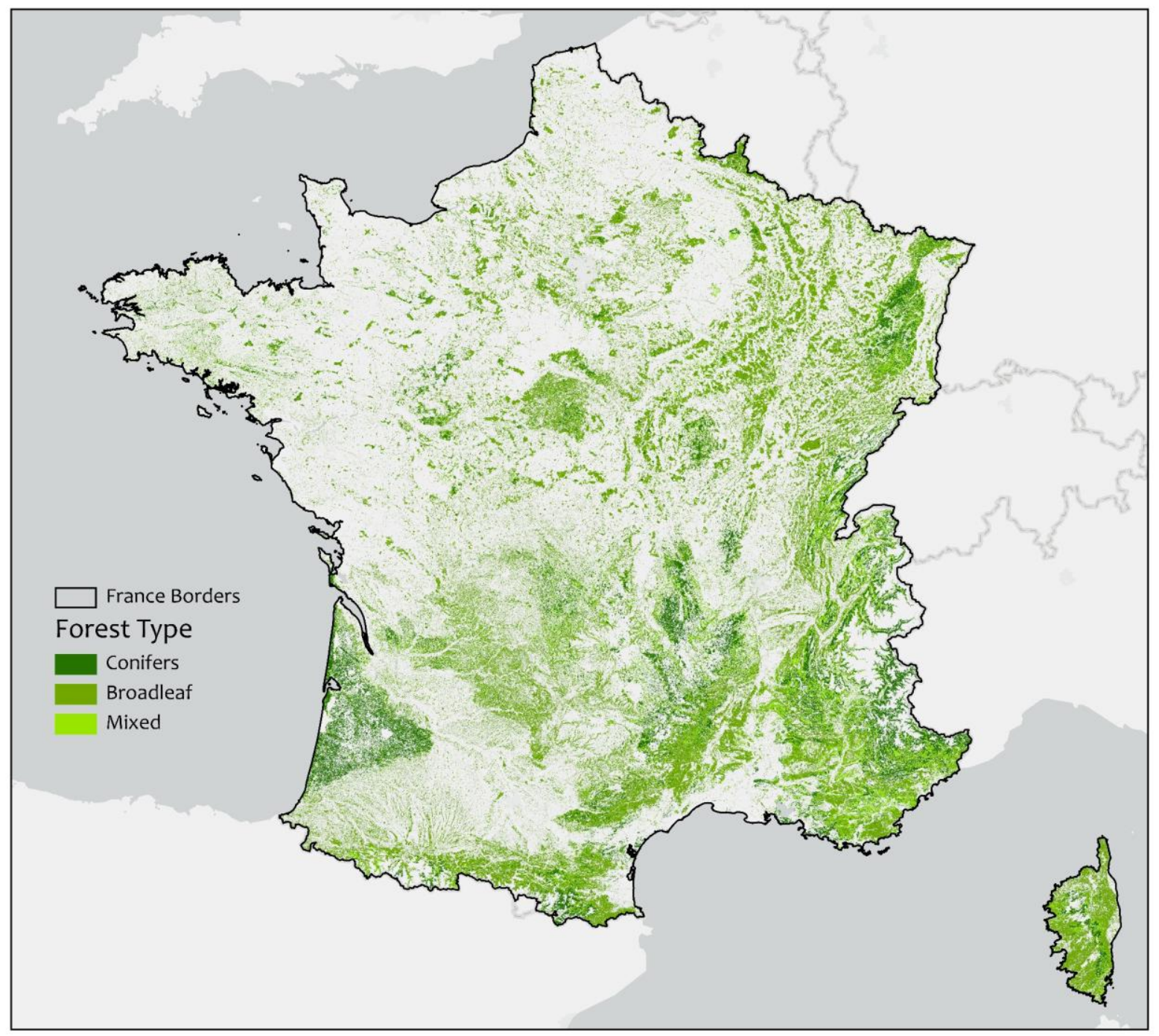

Figure 3: Forest map of Metropolitan France 
The statistical data on GAI and NL (step 1) were retrieved from [77], [78], a dataset built for a national tool called ALDO, which provides an estimate of carbon sequestration in soils and biomass. The ALDO tool contains data on production and mortality among others for conifers, broadleaf and mixed forest types at the French EPCI administrative level. The statistical data from the ALDO tool for every EPCI were added to the administrative EPCI shapefile and converted to the raster format for further processing (step 2). This step was facilitated with the polygon to raster tool in ArcGIS Pro. In this step, the cell or pixel size of the forest raster is determined.

Although the ALDO dataset provided the required GAI and NL data, it did not provide the uncertainty ranges or the standard deviation of these variables. The standard deviation for the calculated NAI was estimated using the standard deviation classification method in ArcGIS Pro [79]. The standard deviation method estimates how much the value of the NAI varies from the mean. The calculated standard deviation value is numerically similar to the standard uncertainty value [63]. For BEF, the uncertainty range provided in the IPCC [53] was used. From this, a low and high spatial estimate of PFRs was calculated using Eq. 5-6.

\subsection{Deciding the spatial resolution}

The main objective of this study was to develop an easily replicable method for high-resolution spatial quantification of above-ground PFRs at the pixel level. Here, high-resolution corresponds to high-spatialresolution, the definition of which is provided in Table 2. Over the years due to the improvements in satellite products and processing techniques this definition has kept on evolving. For example, what was considered as high resolution in the 1980s (LANDSAT 60-meter / pixel), has become low in today's standards. Typically, the resolution of any spatial study is based on the type of data available and the purpose of work. For example, in the study by Hansen et al. [80], high-resolution global maps were produced using Landsat data at a 30-meter spatial resolution to characterize the forest extent, loss and gain from 2000 to 2012 . Another study by Inglada et al. [81] reported using Landsat 8 data (30-meter / pixel) for producing high-resolution land cover maps at the country scale (France). It may be argued that as per current standards a resolution of 30-meter will correspond to being a medium resolution, and high spatial resolution will range anywhere from 10 -meter to the minimum extent possible [82]. On the other hand, the scale or geographic extent of the study is a key determining factor in defining what can be considered as a high resolution or not. Furthermore, creating land cover maps using high-resolution satellite imagery (> 10-meter) has multiple cons. These include high costs, as commercial satellites carrying the most advanced sensors, are expensive; Small coverage area or swath, as the higher the resolution, the less total ground area can be covered in a scene. Contrarily, low spatial resolution data contain lower level of details which might not be suitable for supporting local bioeconomy decisions.

As there are no standard procedures to decide what spatial resolution would be ideal for spatial quantification of PFRs at the country scale, we propose a metric based on computational complexity (in terms of size of data and processing time) and the deviation of estimated results at different spatial resolutions. To test this case, the theoretical potential of above-ground PFRs of conifer forests in the Occitanie region was evaluated. The conifer forest of the Occitanie region was sampled at the spatial resolution of 100-meter, 30-meter, 20-meter, 10-meter, 5-meter, and 1-meter (step 2).

Figure 4 shows the generated forest raster at different spatial resolutions overlaid on a base map. Figure 4 highlights that the coarser resolution data especially the 100-meter one may mask other land cover types, while resolutions of 20-meter and below are less likely to mask other land cover types. On the other hand, the sampling of large vector datasets to smaller cell sizes may excessively enhance the computational budget in terms of processing time and storage [83]. This can be witnessed in Figure 5, where the processing time and the space requirement increases at a logarithmic scale, especially for the data being processed at less than 10-meters. The conversion of complex forest shapefile (Vector) to raster at 1-meter resolution took 20475 seconds, compared to 34 seconds for the same data at 10-meter resolution, which is nearly 600 times more. Similarly, the size of the processed raster image was nearly 80 times more for the 1-meter sampled data (1002314 kilobytes) compared to the 10-meter one (12468 kilobytes). The final uncompressed size of the processed raster containing information on the location and quantity of PFRs for the conifer forest of the Occitanie region was 490 gigabytes for the 1meter resolution data (Supplementary Table 1). The values highlighted in bold in Figure 5 show the increase in the complexity in terms of time per pixel area and file size per pixel area. There is a substantial increase from 10-meter spatial resolution data to 5 -meter data for both processing time and file size. This test was performed only for one 
forest type of one region of France; thus, the estimation of PFRs for the entire country at a very high spatial resolution would be rather tedious.

Supplementary Table 2 shows the results of the theoretical potential of above-ground PFRs (Conifers) for different departments of the Occitanie region in $\mathrm{Mg}_{\text {dry matter }}$ year ${ }^{-1}$ at different spatial resolutions. A pairwise comparison was then made to establish the percentage difference in the results of spatial quantification at different resolutions. This highlights that for most of the cases, the percentage difference in estimation was marginal (>0.2\%). In view of these results, it was decided to select 10-meter as the most optimal resolution based on the computational budget and comparison with other resolutions.
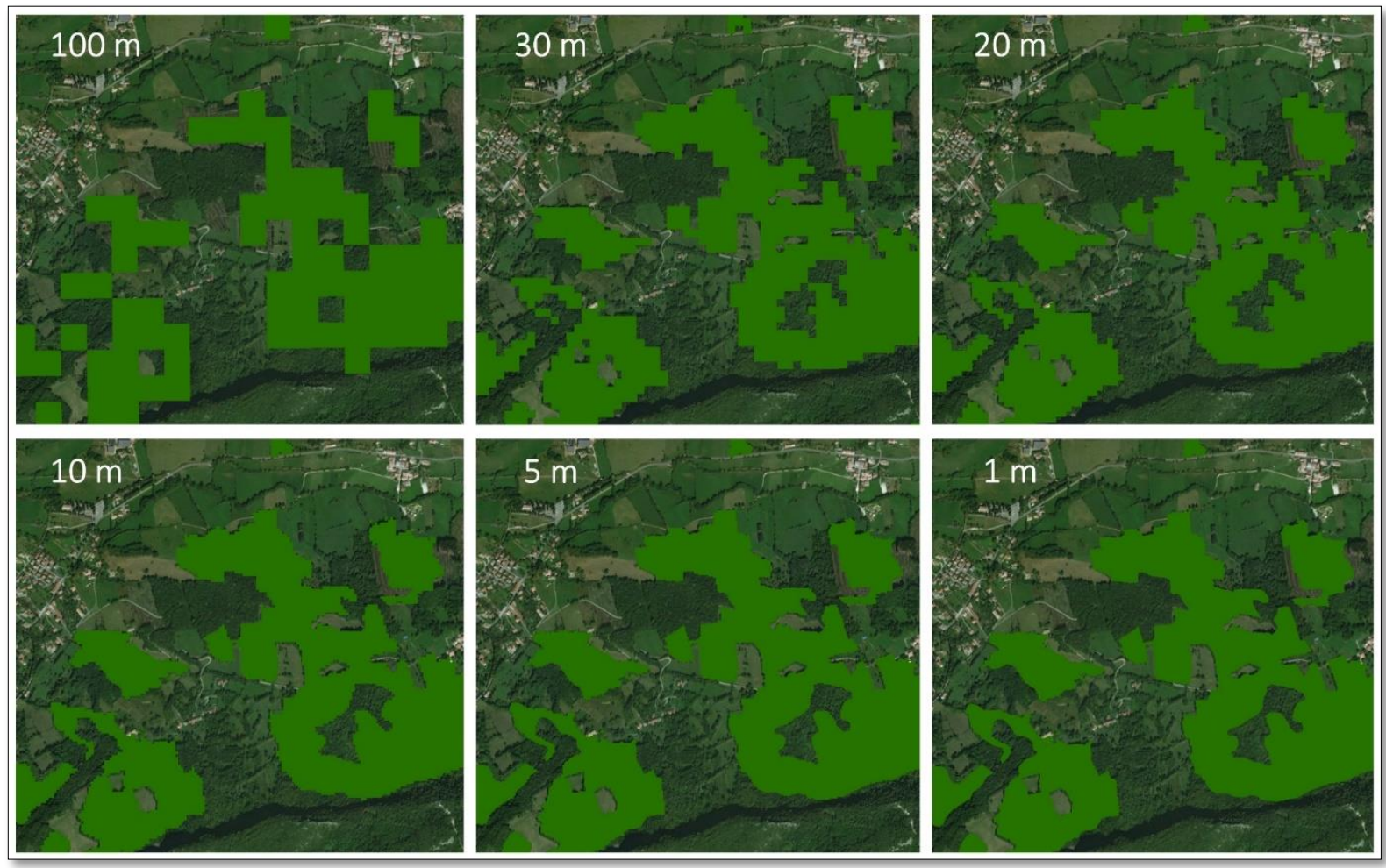

Figure 4: Visual representation of different spatial resolutions for conifers in a given area of the French Occitanie Region. The areas in light green are the areas considered to be conifer forest, for the selected resolution. 


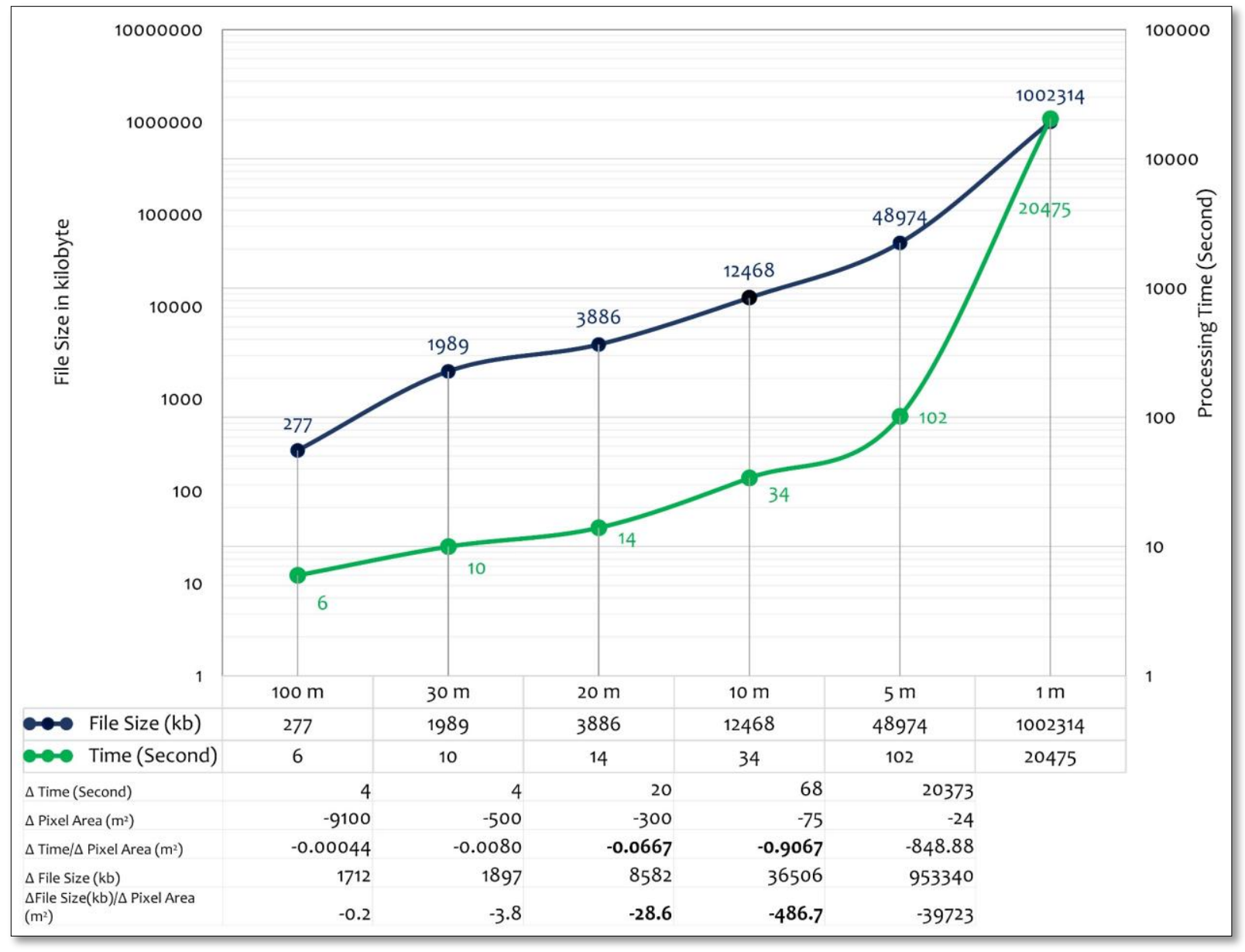

Figure 5: File size and processing time at different spatial resolutions. The labels on the $x$-axis are qualitative and represent the size of a pixel (e.g., $100 \mathrm{~m}$ corresponds to an area of $100^{2} \mathrm{~m}^{2}$ )

\subsection{Exemplification results}

Figure 6 shows the theoretical potential of PFRs for France in terms of $\mathrm{Mg}_{\text {dry matter }}$ year ${ }^{-1}$. The spatial quantification result is illustrated in the form of 10-meter $\times 10$-meter pixels $\left(100 \mathrm{~m}^{2}\right)$, which is the first-ever high-resolution map of available potential of PFRs at a country scale. The advantage of using discrete high-resolution pixels is that it allows for aggregation of these pixels at different administrative levels such as regions of departments. The theoretical potential for PFRs in France, when observed at the pixel level (here $100 \mathrm{~m}^{2}$ per pixel), varies from $\leq$ $0.15 \mathrm{Mgdry} \mathrm{matter} \mathrm{year}^{-1}$ per pixel to a maximum of $0.91 \mathrm{Mgdry}_{\text {matter }}$ year ${ }^{-1}$ per pixel. From Figure 6 it can be observed that the residues are mainly concentrated in the Mediterranean basin in the regions of Occitanie and ProvenceAlpes-Côte d'Azur, the Landes forest in the south-western part of the country in the Nouvelle-Aquitaine region, the east of the country in the Grand-Est and Bourgogne-Franche-Comté regions and in the mountainous region of Auvergne-Rhône-Alpes. The regions in the north and north-west of France have scattered PFRs, reflecting the forest structure in these regions. The island region of Corse, despite having the highest concentration of forests in terms of total percent cover of land area (Supplementary Table 3), produces a rather low quantity of residues (0.15 $-0.45 \mathrm{Mg}_{\text {dry matter year }}{ }^{-1}$ per pixel) in comparison to other French Regions. From a mechanistic viewpoint, the only variable that contributes to the quantity of residues being lower in this region is the annual increment. Similarly, the south-eastern and southern parts of France, especially in the Mediterranean basin have a lower quantity of PFRs, ranging from $\leq 0.15 \mathrm{Mgdry}_{\text {matter } y e a r^{-1}}$ to $0.30 \mathrm{Mg}_{\text {dry }}$ matter $y e a r^{-1}$ per pixel. 


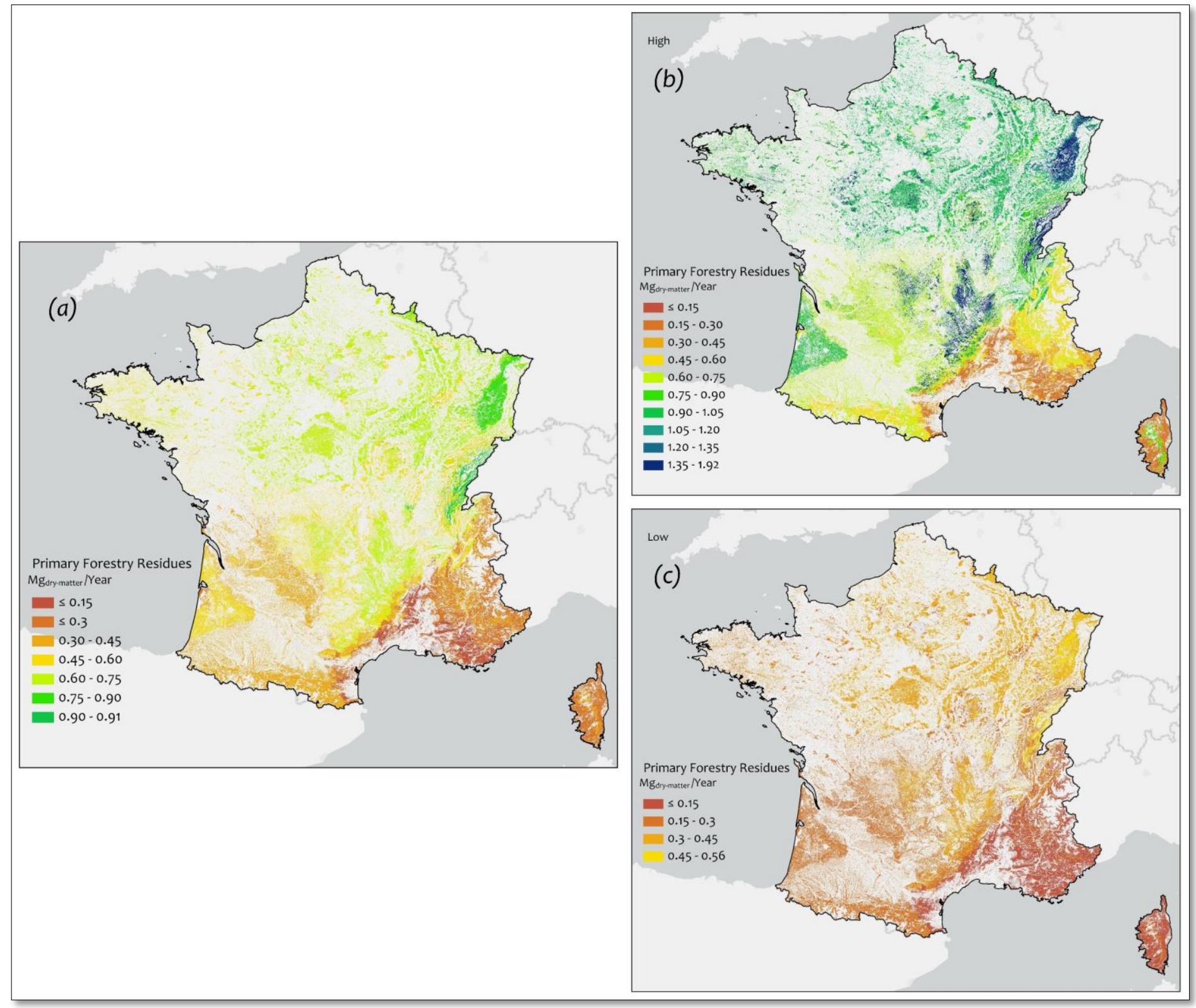

Figure 6: Theoretical potential of (a) primary forestry residues (b) with high uncertainty (c) and low uncertainty at a harmonized scale 
Figure 7 shows the aggregated distribution of PFRs in terms of Million $\mathrm{Mgdry}_{\text {matter }}$ year ${ }^{-1}$ to the departmental and the regional administrative levels, while Table 4 shows the overall absolute potentials per region. The total theoretically available potential of PFRs in France is about 8.4 Million $\mathrm{Mg}_{\text {dry }}$ matter year ${ }^{-1}$, ranging between 4.4 Million $\mathrm{Mg}_{\text {dry matter }}$ year ${ }^{-1}$ with the lower values of the uncertainty range and about 13.9 Million $\mathrm{Mgdry}_{\text {matter }}$ year ${ }^{-1}$ with the higher values of the uncertainty range. The departmental distribution of PFRs is presented in Supplementary Table 4. The Vosges department in the region of Grand-Est has the greatest availability of PFRs at about 0.235 Million $\mathrm{Mg}_{\text {dry matter }}$ year ${ }^{-1}$. All of the regions showed high fluctuation of estimated PFRs between the lower range and higher range values, and nearly all of the higher values were approximately three times more than the lower values for all regions (Table 4 ).

Figure 8 illustrates the distribution of PFRs for private and public forests in France. A clear distinction can be made in the spatial distribution of these resources, as private forests are evenly spread across France compared to the public forests which are concentrated in the region of Grand-Est and other mountainous regions covering the French Alps and the Pyrenees. Private forests having the larger share of forestland naturally produce more forestry residues compared to the public forests. The ratio of produced PFRs for private and public forests is almost 3:1. The cumulative amount of PFRs available from private forests in a year is almost 6.2 Million Mgdry mater, compared to approximately 2.1 Million Mgdry matter for public forests (Table 4).

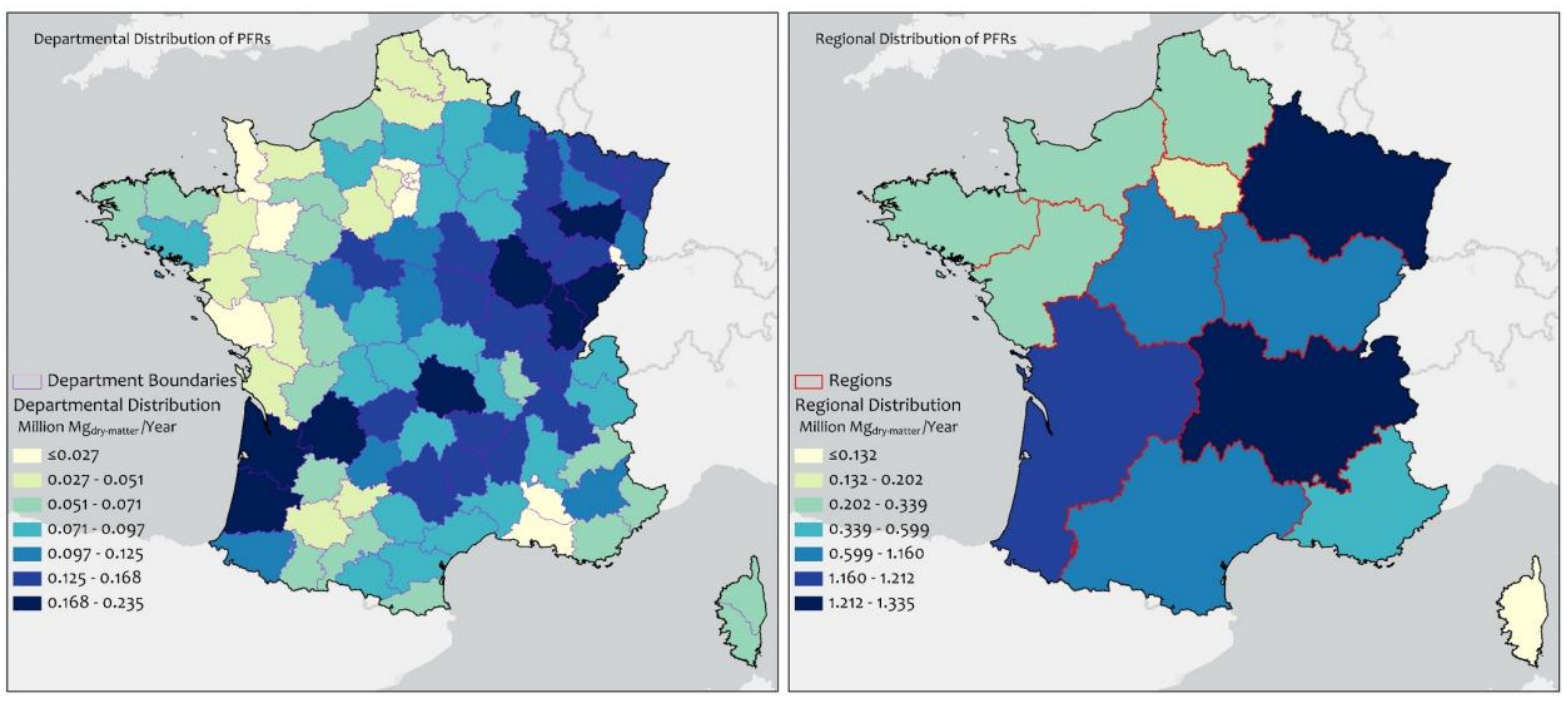

Figure 7: Distribution of PRFs aggregated to departmental and regional administrative levels
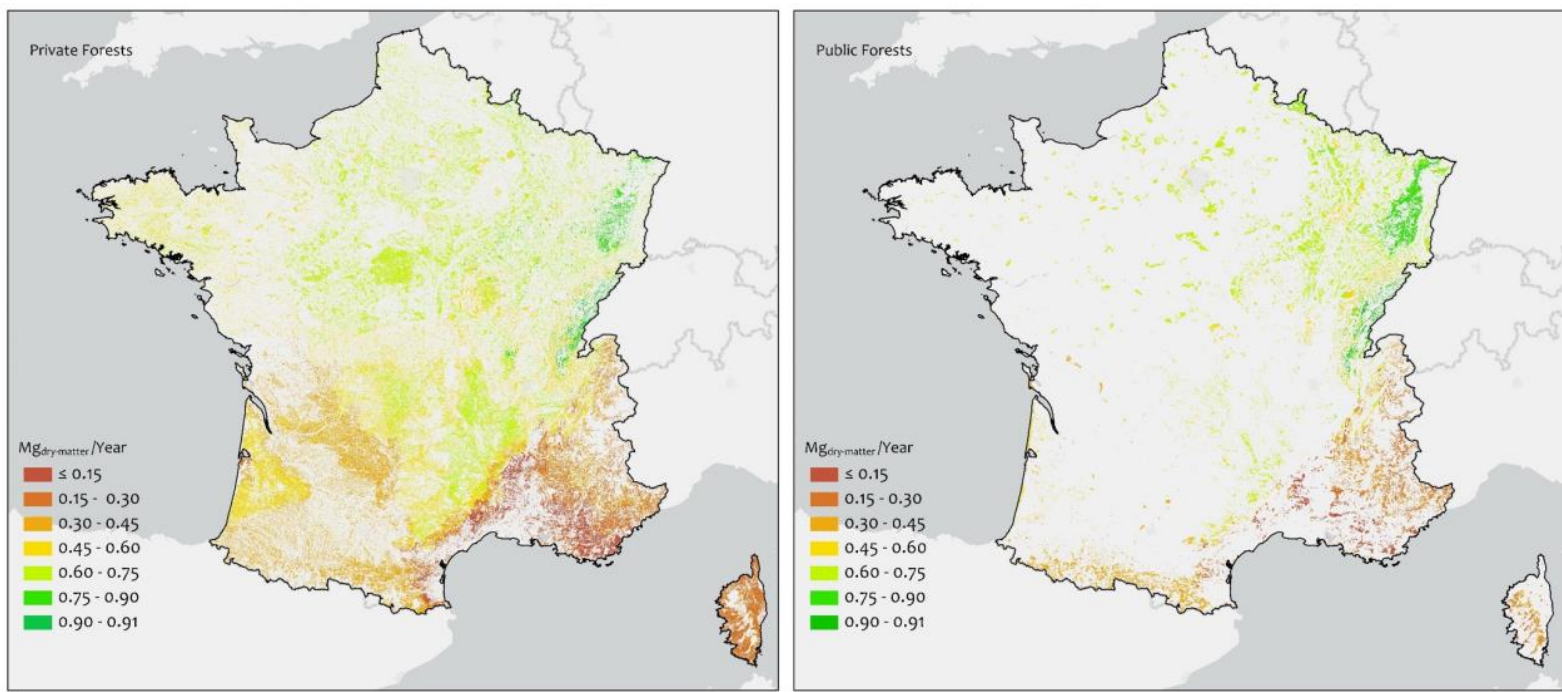

Figure 8: Distribution of PFRs for private and public forests of France 
Table 4: Absolute PFRs produced per region, in Million Mgdry matter year ${ }^{-1}$

\begin{tabular}{|c|c|c|c|c|c|}
\hline & \multicolumn{5}{|c|}{ Million $\mathrm{Mg}_{\text {dry matter year }}{ }^{-1}$} \\
\hline Region Name & Available Potential & Lower Range & Higher Range & Private Forests & Public Forest \\
\hline Auvergne-Rhône-Alpes & 1.316 & 0.708 & 2.292 & 1.067 & 0.249 \\
\hline Bourgogne-Franche-Comté & 1.160 & 0.603 & 1.894 & 0.710 & 0.450 \\
\hline Bretagne & 0.267 & 0.138 & 0.437 & 0.248 & 0.019 \\
\hline Centre-Val de Loire & 0.601 & 0.307 & 0.947 & 0.531 & 0.070 \\
\hline Corse & 0.132 & 0.069 & 0.219 & 0.100 & 0.032 \\
\hline Grand Est & 1.335 & 0.696 & 2.194 & 0.587 & 0.748 \\
\hline Hauts-de-France & 0.287 & 0.146 & 0.442 & 0.216 & 0.071 \\
\hline Île-de-France & 0.177 & 0.090 & 0.273 & 0.124 & 0.053 \\
\hline Normandie & 0.263 & 0.135 & 0.415 & 0.207 & 0.056 \\
\hline Nouvelle-Aquitaine & 1.209 & 0.647 & 2.068 & 1.113 & 0.096 \\
\hline Occitanie & 1.113 & 0.583 & 1.837 & 0.900 & 0.213 \\
\hline Pays de la Loire & 0.206 & 0.109 & 0.341 & 0.187 & 0.019 \\
\hline Provence-Alpes-Côte d'Azur & 0.343 & 0.185 & 0.608 & 0.227 & 0.116 \\
\hline Total & 8.409 & 4.416 & 13.966 & 6.217 & 2.191 \\
\hline
\end{tabular}

A standard uncertainty map (Figure 9) was also synthesized after estimating the higher and lower values of PFRs. The pixels in the standard uncertainty map of PFRs represent the uncertainty in terms of $\mathrm{Mgdry}_{\text {matter year }}{ }^{-1}$ per pixel. The standard uncertainty of availability of PFRs in France ranged from a minimum of $0 \mathrm{Mgdry}_{\text {matter year-1 }}$ to a $^{-1}$ maximum of $0.68 \mathrm{Mg}_{\text {dry matter }}$ year ${ }^{-1}$. From a general visual inspection, the uncertainty was observed to be higher in areas where the available potential for PFRs was also high and lower in areas where the available potential for PFRs was smaller. The standard uncertainty in the spatial quantification of PFRs followed the same spatial pattern as the theoretical potential of PFRs in Figure 6.

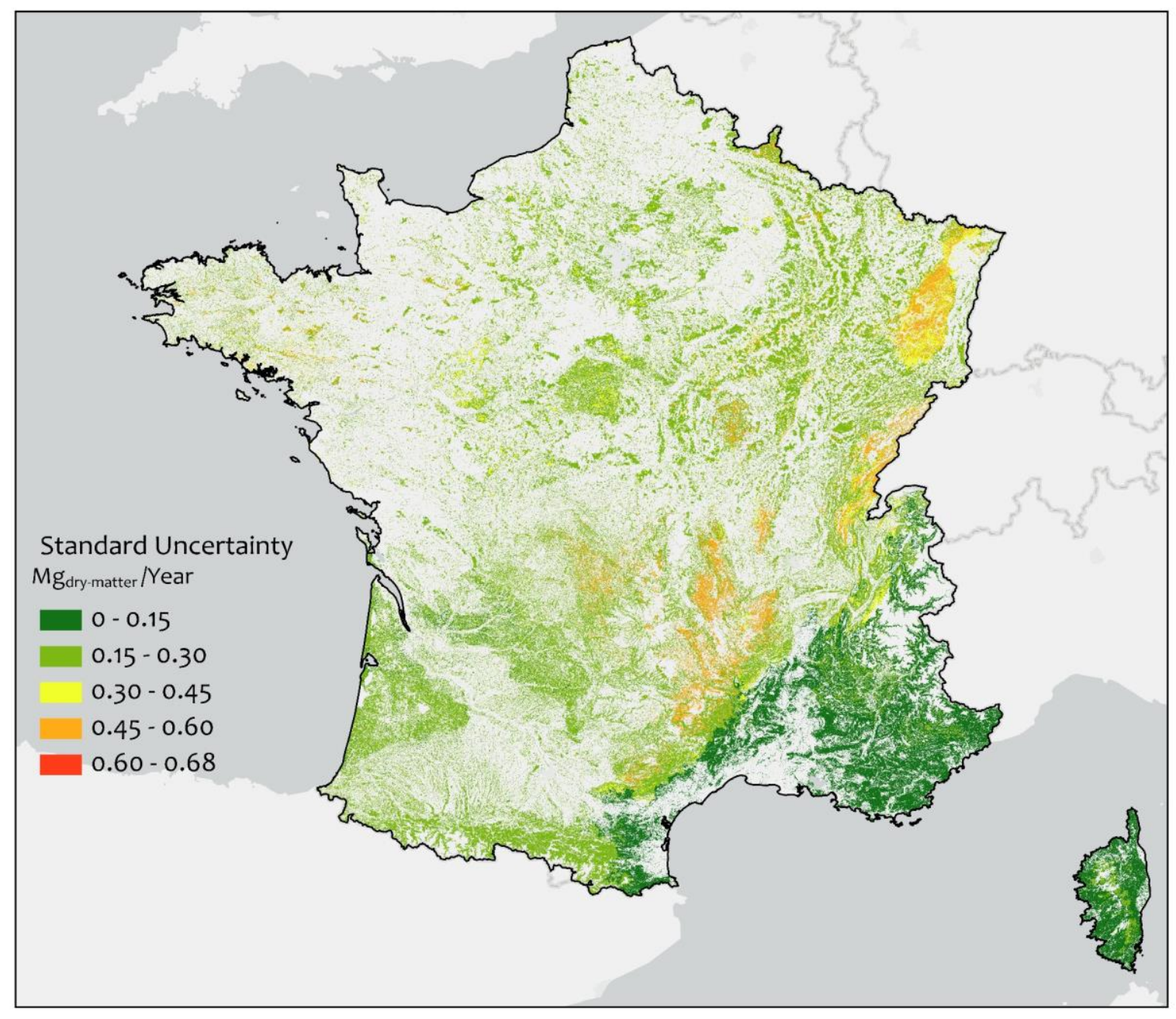

Figure 9: Standard uncertainty in the estimation of Primary Forestry Residues at the pixel level 


\section{Discussion}

The work presented in this study bridges the gap between spatial sciences, forestry, and bioeconomy by providing an easily replicable spatially explicit framework "CamBEE" for estimating PFRs at high resolution. The CamBEE framework can work across wide ranges of geographical scales and spatial resolution with open source data. The study also provides a detailed illustration of the proposed framework and exemplifies its use as a case study for France. What makes the CamBEE framework unique is the explicit incorporation of uncertainties to derive the final PFR estimates. The other existing methods (Table 1 ) do not account for the uncertainty that may be incorporated through the input data or that are propagated through the calculation steps. Our exemplification case for France highlighted that the variability of estimates can reach a relatively high degree; a theoretical PFRs potential ranging from about 4.4 Million $\mathrm{Mgdry}_{\text {matter } y e a r^{-1}}$ to about 13.9 Million $\mathrm{Mgdry}_{\text {matter }}$ year ${ }^{-1}$ was obtained (i.e. ca. doubling or halving the potential estimated without uncertainties). Therefore, the uncertainty must be accounted for when making strategic investment decisions into future bioeconomy technologies.

The framework presented and illustrated in this paper can be used to derive the so-called "theoretical" potential of PFRs. However, as the framework is explicitly described, different restriction conditions can easily be applied within the Geographic Information System (GIS) environment that can be used to yield other potentials. These would then be considered as a step 5 of the CamBEE framework. In fact, many studies express concerns with the maintenance of soil organic carbon as an important ecological service provided by PFR residues [7]. Though essential for bioeconomy strategies [6], [84], quantifying the difference of environmental impacts between the current and potential use of PFR is obviously beyond the scope of the present study, but such assessment can henceforth be made at a spatially-explicit scale using the CamBEE framework.

The exemplification results of the case study were partially validated using the statistical data published by Colin and Thivolle-Cazat [85]. They reported what they refer to as "gross availability" (similar to theoretical potential) for branches and twigs $<7 \mathrm{~cm}$ [86] which roughly translates to PFRs (excluding the foliage and dead or damaged trees) around 6.08 Million Mgdry matter year ${ }^{-1}$ for the years 2016-2020. This data is not directly available in the report [85] as the values for gross availability are provided in $\mathrm{m}^{3}$ year ${ }^{-1}$, but these can be converted to mass by using the IPCC factors of basic wood density [33]. Our final estimated figure for France thus deviates by only $38 \%$ from the national statistical data; we do not claim this as a proof of validation, but it builds confidence around the range found with CAMBEE.

In contrast, the spatially-explicit study of Hamelin et al. [4], where estimates are reported at the European "NUTS$3^{\prime \prime}$ level, reveal a theoretical potential of 455 PJ year $^{-1}$ for PFR in France (results extrapolated from the raw dataset of the authors). This represents ca. 24 Million Mg year-1, based on a lower heating value (LHV) of $19.19 \mathrm{GJ} \mathrm{Mg}^{-1}$ [8], which is nearly 3 -fold the potential found in our study. The higher value reported in [4] is explained by (i) the inclusion of stumps as a residual component of the stream, and (ii) the methodological framework itself, where country level data on forest statistics were simply (and coarsely) scaled down to different administrative regions. Conversely, our framework aggregates pixel level data to different administrative regions following a bottom-up approach, thus avoiding inconsistencies in the resolution of the dataset used, and providing more reliable estimates. This indicates that the results of [4] may be overestimated, and accordingly that the residual biomass potential generated in Europe might be lower than previously anticipated.

The results obtained from the CamBEE framework are only as good as the input data supplied. Although the uncertainty assessment tries to capture the deviation as ranges, uncertain data will make this range large. In the exemplification section, the forest increment statistics that are derived from [78] uses the statistical data of the French intercommunal plans for energy and climate (89; PCAET), which in turn cross-reference the NFI survey data with the 11 French Biome Regions (GRECO; [88]) and the French Forestry Regions (SER; [88]) data. The GRECO and SER data describe the climate, geology and geomorphology, hydrography, soils, vegetation, land-use, and forest landscape. The common spatial pattern irrespective of the numerical ranges in the derived maps of France follows the same spatial pattern of the GRECO and SER. The question of how this imposed spatial pattern affects the actual availability of PFRs on the field remains unanswered and can only be verified by extensive field sampling.

Furthermore, it should be highlighted that the results obtained from the CamBEE framework are a representation of the past. In our case study, we use data from different periods, e.g. the forest map is developed by combining field data from multiple observations at different places with remote sensing data on forest structure (Table 3). The statistical data on the factor of basic wood density and biomass expansion also comes from the IPCC report [53] which was published in 2003. Using data from different time periods may also lead to additional uncertainty 
in the results which is not captured here. Notwithstanding, data from simulations on future forest cover and productivity can be used with the CamBEE framework to estimate the PFRs for the future. This could be particularly needed in order to anticipate the changes in PFR potential following e.g. exposure to a warmer climate, or mitigation strategies applied in the forestry sector (e.g. shift from less drought-tolerant species to more tolerant ones).

Moreover, the value of BEFs is contingent on several factors out of which climatic regime of the area and soil attributes are region-specific. BEF are factors widely used to estimate carbon stocks in forests, allowing to estimate the total above-ground biomass generated by a given class of tree (broad leaves, conifer), knowing the minimum diameter at breast height. Most practitioners rely, as in this study, on the estimates provided by the IPCC [53]. However, the IPCC provides these BEF values as coarse aggregated figures for wide biomes (e.g. temperate). In this way, the use of this factor can be seen as a limitation. Nevertheless, the BEF values are provided as ranges in the IPCC, so it is expected that any spatial variation coming from regional attributes will be captured within these ranges.

In terms of energy, 8.4 Million Mgdry matter year ${ }^{-1}$ directly translates to ca. 161.2 PJ year-1 (considering a LHV of 19.19 GJ Mg${ }^{-1}$ ). This represents about $2.5 \%$ of France's 2017 energy consumption [86]. The total available potential of PFRs in this assessment includes both private and public forests, with a substantial quantity of these residues (about 74\%) lying with private owners. In a survey study involving 800 forest owners across Sweden, Germany and Portugal, Blennow et al. [89] suggest that private forest owners in Europe may not be willing to contribute to mobilizing the available stemwood for different bioeconomic purposes, which in turns involve no residues generation. However, Stjepan et al. [90] reported that forest owners in South-Eastern Europe are more willing to manage their forests in mobilizing woody biomass for bioeconomic purposes. This highlights the critical importance of these private forest owners as stakeholders to mobilize towards sustainable bioeconomy strategies.

\section{Conclusions}

The essential contributions of the present study are summarized as:

- A generic, transparent and step-wise methodology for spatial quantification of PFRs at the pixel level incorporating associated uncertainties was developed. The applicability of the proposed methodology was tested and demonstrated for the case of Metropolitan France. The results indicated not only that the

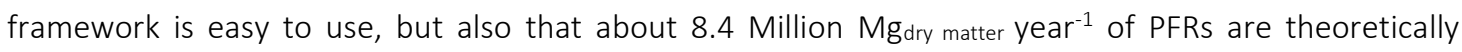
available for the bioeconomy in France.

- The uncertainty quantification of PFRs revealed that the available potential of PFRs ranged from about 4.4 Million $\mathrm{Mgdry}_{\text {matter }} \mathrm{Yr}^{-1}$ to about 13.9 Million $\mathrm{Mg}_{\text {dry matter }} \mathrm{Yr}^{-1}$. This large range highlighted the importance of quantifying uncertainties.

- A clear and transparent procedure to decide the spatial resolution was presented. From this, we concluded that processing data at very high spatial resolution $(<5$-meter) might not necessarily yield better results; instead, it may unnecessarily increase the computational budget without adding any extra value.

\section{Acknowledgments}

This work was carried out within the framework of the research project Cambioscop (https://cambioscop.cnrs.fr) and was partly financed by the French National Agency, Programme Investissement d'Avenir (ANR-17-MGPA0006) and Region Occitanie (18015981). The authors gratefully acknowledge Dr. Antoine Collin of IGN for insightful discussions, advice, and the access to BD Forêt version 2 data and to Dr. Laurent Polidori and Dr. Jordi Inglada of CESBIO for sharing the land cover data of Metropolitan France. The authors further acknowledge Miriam Buitrago of ADEME for the ALDO tool.

\section{References:}

[1] IPCC, "Summary for Policymakers. In: Global Warming of $1.5^{\circ} \mathrm{C}$. An IPCC Special Report on the impacts of global warming of $1.5^{\circ} \mathrm{C}$ above pre-industrial levels and related global greenhouse gas emission pathways, in the context of strengthening the global response to," and T. W. (eds. . Masson-Delmotte, V., P. Zhai, H.-O. Pörtner, D. Roberts, J. Skea, P.R. Shukla, A. Pirani, W. Moufouma-Okia, C. Péan, R. Pidcock, S. Connors, J.B.R. Matthews, Y. Chen, X. Zhou, M.I. Gomis, E. Lonnoy, T. Maycock, M. Tignor, Ed. Oxford, UK: World Meteorological Organization, Geneva, Switzerland, 32 pp., 2018.

[2] C. Le Quéré et al., "Global carbon budget 2014," Earth Syst. Sci. Data, vol. 7, no. 1, pp. 47-85, 2015.

[3] UN, "Paris Agreement," 2015.

[4] L. Hamelin, M. Borzęcka, M. Kozak, and R. Pudełko, "A spatial approach to bioeconomy: Quantifying the residual biomass potential in the EU-27," Renew. Sustain. Energy Rev., vol. 100, no. November 2018, pp. 127-142, 2019. 

unavoidable wastes from processing," Resour. Conserv. Recycl., vol. 149, no. November 2018, pp. 413-426, 2019.

[6] D. Tonini, L. Hamelin, and T. F. Astrup, "Environmental implications of the use of agro-industrial residues for biorefineries: application of a deterministic model for indirect land-use changes," GCB Bioenergy, vol. 8, no. 4, pp. 690-706, 2016.

[7] V. Daioglou, E. Stehfest, B. Wicke, A. Faaij, and D. P. van Vuuren, "Projections of the availability and cost of residues from agriculture and forestry," GCB Bioenergy, vol. 8, no. 2, pp. 456-470, 2016.

[8] P. Ruiz et al., The JRC-EU-TIMES model. Bioenergy potentials for EU and neighbouring countries. European Commission Joint Research Centre, 2015.

[9] J. D. Walmsley and D. L. Godbold, "Stump harvesting for bioenergy - A review of the environmental impacts," Forestry, vol. 83, no. 1, pp. 17-38, 2010

[10] L. Kaarakka et al., "Stump harvesting in Picea abies stands: Soil surface disturbance and biomass distribution of the harvested stumps and roots," For. Ecol. Manage., vol. 425, no. March, pp. 27-34, 2018.

[11] T. Persson and G. Egnell, "Stump harvesting for bioenergy: A review of climatic and environmental impacts in northern Europe and America," WIREs Energy Environ., vol. 7, no. 6, p. e307, 2018.

[12] A. THIVOLLE-CAZAT and É. LE NET, "La mobilisation de la ressource forestière aujourd’hui et demain," Rev. For. Française, no. 4, p. Fr.], ISSN 0035, 2015.

[13] J. Barrette, D. Paré, F. Manka, L. Guindon, P. Bernier, and B. Titus, "Forecasting the spatial distribution of logging residues across the Canadian managed forest," Can. J. For. Res., vol. 48, no. 12, pp. 1470-1481, Dec. 2018.

[14] J. Návar, "Measurement and assessment methods of forest aboveground biomass: a literature review and the challenges ahead," in Biomass, M. Momba and F. Bux, Eds. Sciyo: Rijeka, Croatia, 2010, pp. 27-64.

[15] Food and Agriculture Organization-FAO, Global Forest Resources Assessment 2015. 2015.

[16] "Raw data - FOREST INVENTORY." [Online]. Available: https://inventaire-forestier.ign.fr/spip.php?rubrique159. [Accessed: 06-Sep2019].

[17] C. Vidal, I. Alberdi, J. Redmond, M. Vestman, A. Lanz, and K. Schadauer, "The role of European National Forest Inventories for international forestry reporting," Ann. For. Sci., vol. 73, no. 4, pp. 793-806, 2016.

[18] T. Gschwantner et al., "Comparison of methods used in European National Forest Inventories for the estimation of volume increment: towards harmonisation," Ann. For. Sci., vol. 73, no. 4, pp. 807-821, 2016.

[19] COST, "COST Action E43 Harmonisation of national Inventories in Europe : Techniques for Common Reporting," p. 43, 2008.

[20] J. Zhang, P. Atkinson, and M. F. Goodchild, Scale in Spatial Information and Analysis, 1st Editio. Boca Raton: CRC Press, 2014.

[21] F. López-Rodríguez, C. P. Atanet, F. C. Blázquez, and A. R. Celma, "Spatial assessment of the bioenergy potential of forest residues in the western province of Spain, Caceres," Biomass and Bioenergy, vol. 33, no. 10, pp. 1358-1366, 2009.

[22] H. Vasco and M. Costa, "Quantification and use of forest biomass residues in Maputo province, Mozambique," Biomass and Bioenergy, vol. 33, no. 9, pp. 1221-1228, Sep. 2009.

[23] H. Viana, W. B. Cohen, D. Lopes, and J. Aranha, "Assessment of forest biomass for use as energy. GIS-based analysis of geographical availability and locations of wood-fired power plants in Portugal," Appl. Energy, vol. 87, no. 8, pp. 2551-2560, 2010.

[24] L. A. Wells, W. Chung, N. M. Anderson, and J. S. Hogland, "Spatial and temporal quantification of forest residue volumes and delivered costs," Can. J. For. Res., vol. 46, no. 6, pp. 832-843, 2016.

[25] L. A. Wells, "Spatial Distribution and Quantification of Forest Treatment Residues for Bioenergy Production," University of Montana, 2013.

[26] L. Guindon et al., "Annual mapping of large forest disturbances across Canada's forests using 250 m MODIS imagery from 2000 to 2011," Can. J. For. Res., vol. 44, no. 12, pp. 1545-1554, 2014.

[27] L. Guindon et al., "Canada Landsat Disturbance (CanLaD): a Canada-wide Landsat-based 30-m resolution product of fire and harvest detection and attribution since 1984." 2017.

[28] N. Greggio et al., "Theoretical and unused potential for residual biomasses in the emilia Romagna Region (Italy) through a revised and portable framework for their categorization," Renew. Sustain. Energy Rev., vol. 112, no. June, pp. 590-606, 2019.

[29] M. W. Vis, D. van den Berg, and E. Al., "Best Practices and Methods Handbook," vol. D 5.3, pp. 1-220, 2010.

[30] D. Domingo et al., "Quantifying forest residual biomass in Pinus halepensis Miller stands using Airborne Laser Scanning data," GIScience Remote Sens., vol. 0, no. 0, pp. 1-23, 2019.

[31] B. Batidzirai, E. M. W. Smeets, and A. P. C. Faaij, "Harmonising bioenergy resource potentials - Methodological lessons from review of state of the art bioenergy potential assessments," Renew. Sustain. Energy Rev., vol. 16, no. 9, pp. 6598-6630, 2012.

[32] H. Herrmann and H. Bucksch, “Chapter 4: Forest Land (IPCC 2006 Guidelines)," Dict. Geotech. Eng. Geotech., pp. 556-556, 2014.

[33] Jim Penman et al., "Good Practice Guidance for Land Use, Land-Use Change and Forestry," 2003.

[34] F. Castedo-Dorado, E. Gómez-García, U. Diéguez-Aranda, M. Barrio-Anta, and F. Crecente-Campo, "Aboveground stand-level biomass estimation: A comparison of two methods for major forest species in northwest Spain," Ann. For. Sci., vol. 69, no. 6, pp. 735-746, 2012.

[35] FAO FRA, "Forest Resources Assessment 2015: Terms and Definitions," FAO Rep., p. 36, 2012.

[36] S. Liang, X. Li, and J. Wang, "A Systematic View of Remote Sensing," in Advanced Remote Sensing, Elsevier, 2012, pp. 1-31.

[37] "What is raster data?-Help | ArcGIS for Desktop." [Online]. Available: http://desktop.arcgis.com/en/arcmap/10.3/managedata/raster-and-images/what-is-raster-data.htm. [Accessed: 04-Sep-2019].

[38] X.-P. Song et al., "Global land change from 1982 to 2016," Nature, vol. 560, no. 7720, pp. 639-643, 2018.

[39] L. Qin, Q. Liu, M. Zhang, and S. Saeed, "Effect of measurement errors on the estimation of tree biomass," Can. J. For. Res., vol. 49, no. 11, pp. 1371-1378, Nov. 2019.

[40] N. S.-N. Lam and D. A. Quattrochi, "On the Issues of Scale, Resolution, and Fractal Analysis in the Mapping Sciences," Prof. Geogr., vol. 44, no. 1, pp. 88-98, Feb. 1992.

[41] G. J. Camia A., Robert N., Jonsson R., Pilli R., García-Condado S., López-Lozano R., van der Velde M., Ronzon T., Gurría P., M’Barek R., Tamosiunas S., Fiore G., Araujo R., Hoepffner N., Marelli L., "Biomass production, supply, uses and flows in the European Union: First results from an integrated assessment," Publications Office of the European Union, 2018, 2018.

[42] G. Resch, A. Held, T. Faber, C. Panzer, F. Toro, and R. Haas, "Potentials and prospects for renewable energies at global scale," Energy Policy, vol. 36, no. 11, pp. 4048-4056, 2008.

[43] Joint Committee For Guides In, "Evaluation of measurement data - Guide to the expression of uncertainty in measurement," Int. Organ. Stand. Geneva ISBN, vol. 50, no. September, p. 134, 2008.

[44] "Shapefiles-ArcGIS Online Help | ArcGIS." [Online]. Available: https://doc.arcgis.com/en/arcgis-online/reference/shapefiles.htm. [Accessed: 06-Sep-2019].

[45] E.-E. Commission, "A new EU Forest Strategy: For forests and the forest-based sector.," Commun. from Comm. to Eur. Parliam. Councis, Eur. Econ. Soc. Comm. Comm. Reg. Brussels., Dec. 2013. 

2019].

[47] "Inventory Review Reports 2019 | UNFCCC." [Online]. Available: https://unfccc.int/process-and-meetings/transparency-andreporting/reporting-and-review-under-the-convention/greenhouse-gas-inventories-annex-i-parties/inventory-reviewreports/inventory-review-reports-2019. [Accessed: 23-Sep-2019].

[48] G. E. Kindermann, I. McCallum, S. Fritz, and M. Obersteiner, "A global forest growing stock, biomass and carbon map based on FAO statistics," Silva Fenn., vol. 42, no. 3, pp. 387-396, 2008.

[49] R. Rengarajan, A. Sampath, J. Storey, and M. Choate, "Validation of geometric accuracy of global land survey (GLS) 2000 data," Photogramm. Eng. Remote Sensing, vol. 81, no. 2, pp. 131-141, 2015.

[50] "Download CCI LC Products | ESA CCI Land cover website." [Online]. Available: https://www.esa-landcover-cci.org/?q=node/164. [Accessed: 12-Dec-2019].

[51] C. Jun, Y. Ban, and S. Li, "Open access to Earth land-cover map," Nature, vol. 514, no. 7523, p. $434,2014$.

[52] EEA, Corine land cover 2000. Technical guidelines. 2002.

[53] IPCC, Good Practice Guidance for Land Use, Land-Use Change and Forestry. 2003.

[54] G. Reyes, S. Brown, J. Chapman, and A. E. Lugo, "Wood Densities of Tropical Tree Species," 1992.

[55] P. Schroeder, S. Brown, J. Mo, R. Birdsey, and C. Cieszewski, "Biomass Estimation for Temperate Broadleaf Forests of the United States Using Inventory Data," For. Sci., vol. 43, no. 3, pp. 424-434, 1997.

[56] C. R. Sanquetta, A. P. D. Corte, and F. da Silva, "Biomass expansion factor and root-to-shoot ratio for Pinus in Brazil," Carbon Balance Manag., vol. 6, no. 1, p. 6, Dec. 2011.

[57] D. Schoene, W. Killmann, H. Von Lupke, and M. LoycheWilkie, "Definitional issues related to reducing emission from deforestation in developing countries," FAO Rep., no. 5, pp. 1-26, 2007.

[58] FAO, Forest Resources of Europe, CIS, North America, Australia, Japan and New Zealand (TBFRA-2000), vol. 81, no. 17. 2000.

[59] J. A. Westfall and R. E. McRoberts, "An assessment of uncertainty in volume estimates for stands reconstructed from tree stump information," Forestry, vol. 90, no. 3, pp. 404-412, Jan. 2017.

[60] R. E. McRoberts and J. A. Westfall, "Propagating uncertainty through individual tree volume model predictions to large-area volume estimates," Ann. For. Sci., vol. 73, no. 3, pp. 625-633, 2016.

[61] A. Kuliešis, S. M. Tomter, C. Vidal, and A. Lanz, "Estimates of stem wood increments in forest resources: comparison of different approaches in forest inventory: consequences for international reporting: case studyof European forests," Ann. For. Sci., vol. 73, no. 4, pp. 857-869, 2016.

[62] F. L. Schmidt and J. E. Hunter, "Theory Testing and Measurement Error," Intelligence, vol. 27, no. 3, pp. 183-198, Sep. 1999.

[63] I. Farrance and R. Frenkel, "Uncertainty of Measurement: A Review of the Rules for Calculating Uncertainty Components through Functional Relationships.," Clin. Biochem. Rev., vol. 33, no. 2, pp. 49-75, May 2012.

[64] B. P. Weidema and M. S. Wesnæs, "Data quality management for life cycle inventories - an example of using data quality indicators," J. Clean. Prod., vol. 4, no. 3-4, pp. 167-174, Jan. 1996.

[65] European Commission, A sustainable Bioeconomy for Europe: strengthening the connection between economy, society and the environment. 2018.

[66] "Over $40 \%$ of the EU covered with forests - Product - Eurostat." [Online]. Available: https://ec.europa.eu/eurostat/web/productseurostat-news/-/EDN-20180321-1. [Accessed: 13-Dec-2019].

[67] IGN, "Le mémento," Inven. For. Natl., p. 29, 2017.

[68] F. Schmithusen and F. Hirsch, "Private forest ownership in Europe," Geneva Timber For. Study Pap. 26, UNECE, pp. 1-120, 2010.

[69] IGN, "Le mémento," Inven. For. Natl., p. 29, 2017.

[70] "Forests in France - GEVES." [Online]. Available: https://www.geves.fr/variety-seed-expertise/forest/forestry-in-france/. [Accessed: 13-Dec-2019].

[71] "BD Forêt ${ }^{\circledR}$ | IGN - Professional Area." [Online]. Available: http://professionnels.ign.fr/bdforet. [Accessed: 08-Oct-2019].

[72] "LES BASES VECTORIELLES." pp. 1-52, 2018.

[73] "Ademe PTC." [Online]. Available: https://www.territoires-climat.ademe.fr/actualite/loutil-aldo-pour-une-premiere-estimation-dela-sequestration-carbone-dans-les-sols-et-la-biomasse. [Accessed: 11-Oct-2019].

[74] "GADM." [Online]. Available: https://gadm.org/. [Accessed: 11-Oct-2019].

[75] "Contours of EPCI 2015 - data.gouv.fr." [Online]. Available: https://www.data.gouv.fr/fr/datasets/contours-des-epci-2015/. [Accessed: 11-Oct-2019].

[76] "Public forests (public distribution) - data.gouv.fr." [Online]. Available: https://www.data.gouv.fr/fr/datasets/forets-publiquesdiffusion-publique/. [Accessed: 14-Oct-2019].

[77] A. Colin, M. Simon, E. Roos, and Y. Schwarz, "Contribution de l'IGN à l'établissement des bilans carbone des forêts des territoires (PCAET)," 2019.

[78] "Ademe PTC." [Online]. Available: https://www.territoires-climat.ademe.fr/actualite/loutil-aldo-pour-une-premiere-estimation-dela-sequestration-carbone-dans-les-sols-et-la-biomasse. [Accessed: 13-Dec-2019].

[79] "Data classification methods-ArcGIS Pro | Documentation." [Online]. Available: https://pro.arcgis.com/en/proapp/help/mapping/layer-properties/data-classification-methods.htm. [Accessed: 10-Dec-2019].

[80] M. C. Hansen et al., "High-Resolution Global Maps of 21st-Century Forest Cover Change," Science (80-. )., vol. 342, no. 6160, pp. 850 LP - 853, Nov. 2013.

[81] J. Inglada, A. Vincent, M. Arias, B. Tardy, D. Morin, and I. Rodes, "Operational High Resolution Land Cover Map Production at the Country Scale Using Satellite Image Time Series," Remote Sens., vol. 9, no. 1, p. 95, 2017.

[82] "Satellite Data: What Spatial Resolution Is Enough for You?" [Online]. Available: https://eos.com/blog/satellite-data-what-spatialresolution-is-enough-for-you/. [Accessed: 10-Oct-2019].

[83] N. Martinkus, G. Latta, T. Morgan, and M. Wolcott, "A comparison of methodologies for estimating delivered forest residue volume and cost to a wood-based biorefinery," Biomass and Bioenergy, vol. 106, pp. 83-94, 2017.

[84] P. Brassard, S. Godbout, and L. Hamelin, "Framework for the consequential life cycle assessment of pyrolysis biorefineries: A case study for the conversion of primary forestry residues."

[85] A. Colin and A. Thivolle, “Disponibilites Forestieres Pour l'Energie Et Les Materiaux à l'Horizon 2035," Ademe, pp. 1-91, 2016.

[86] "Data tables - Data \& Statistics - IEA." [Online]. Available: https://www.iea.org/data-and-statistics/datatables?country=FRANCE\&energy=Balances\&year=2017. [Accessed: 17-Dec-2019].

[87] A. Colin, M. Simon, E. Roos, and Y. Schwarz, "Contribution de l'IGN à l'établissement des bilans carbone des forêts des territoires (PCAET)," 2019.

[88] "Large ecological regions (GRECO) | geo.data.gouv.fr." [Online]. Available: https://geo.data.gouv.fr/fr/datasets/6c8a6dc109c93f05365752e494ba4643dce882fa. [Accessed: 20-Dec-2019] 
[89] K. Blennow, E. Persson, M. Lindner, S. P. Faias, and M. Hanewinkel, "Forest owner motivations and attitudes towards supplying biomass for energy in Europe," Biomass and Bioenergy, vol. 67, pp. 223-230, 2014

[90] P. Stjepan et al., "Private forest owners' willingness to supply woody biomass in selected South-Eastern European countries," Biomass and Bioenergy, vol. 81, no. 2015, pp. 144-153, 2015. 